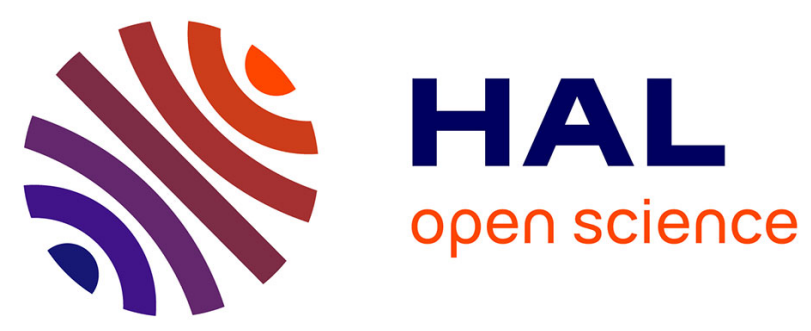

\title{
pH-responsive mesoporous silica drug delivery system, its biocompatibility and co-adsorption/co-release of 5-Fluorouracil and Naproxen
}

Eva Beňová, Virginie Hornebecq, Vladimír Zeleňák, Veronika Huntošová, Miroslav Almáši, Mariana Máčajová, David Bergé-Lefranc

\section{To cite this version:}

Eva Beňová, Virginie Hornebecq, Vladimír Zeleňák, Veronika Huntošová, Miroslav Almáši, et al.. pH-responsive mesoporous silica drug delivery system, its biocompatibility and coadsorption/co-release of 5-Fluorouracil and Naproxen. Applied Surface Science, 2021, 561, pp.150011. 10.1016/j.apsusc.2021.150011 . hal-03518568

\section{HAL Id: hal-03518568 \\ https://hal-amu.archives-ouvertes.fr/hal-03518568}

Submitted on 11 Jan 2022

HAL is a multi-disciplinary open access archive for the deposit and dissemination of scientific research documents, whether they are published or not. The documents may come from teaching and research institutions in France or abroad, or from public or private research centers.
L'archive ouverte pluridisciplinaire HAL, est destinée au dépôt et à la diffusion de documents scientifiques de niveau recherche, publiés ou non, émanant des établissements d'enseignement et de recherche français ou étrangers, des laboratoires publics ou privés. 
Full Length Article

\title{
pH-responsive mesoporous silica drug delivery system, its biocompatibility and co-adsorption/co-release of 5-Fluorouracil and Naproxen
}

\author{
Eva Beňová ${ }^{\mathrm{a}, \mathrm{b}}$, Virginie Hornebecq, ${ }^{\mathrm{b}, *}$, Vladimír Zeleňák ${ }^{\mathrm{a}, *}$, Veronika Huntošovác \\ Miroslav Almáši ${ }^{a}$, Mariana Máčajová ${ }^{\mathrm{d}}$, David Bergé-Lefranc ${ }^{\mathrm{e}}$ \\ ${ }^{a}$ Department of Inorganic Chemistry, Faculty of Science, P.J. Šafárik University, Moyzesova 11, SK-041 54 Košice, Slovakia \\ ${ }^{\mathrm{b}}$ Aix Marseille Univ, CNRS, Madirel, Marseille, France \\ ${ }^{c}$ Center for Interdisciplinary Biosciences, Technology and Innovation Park, P. J. Šafárik University in Košice, Jesenná 5, 04154 Košice, Slovakia \\ d Institute of Animal Biochemistry and Genetics, Centre of Biosciences, Slovak Academy of Sciences, Dúbravská cesta 9, 840 05 Bratislava, Slovakia \\ e Aix Marseille Univ, CNRS, IMBE, Faculté de Pharmacie, Marseille, France
}

\section{A R T I C L E I N F O}

\section{Keywords:}

Drug delivery system

pH-responsive silica

Co-adsorption

Co-delivery

Cytotoxicity

\begin{abstract}
A B S T R A C T
A pH-responsive drug delivery system composed of $\mathrm{N}$-(propyl)aniline (N-ANI) modified mesoporous silica nanoparticles as a carrier, and $\beta$-cyclodextrin $(\beta-\mathrm{CD})$ as a cap was prepared and investigated. The system was studied for co-adsorption and co-delivery of two different drugs; an anticancer drug 5-fluorouracil (5-FU), and anti-inflammatory agent naproxen (NAP). Detailed adsorption study of the drugs themselves as well as in their mutual mixture was performed. The drug release experiments were realized in simulated body fluid $(\mathrm{pH}=7.4)$ and slightly acidic medium $(\mathrm{pH}=5)$ imitating the $\mathrm{pH}$ of tumor affected area. The experiments showed, that at physiological $\mathrm{pH} 7.4$, the prepared drug delivery system released no drug, at slightly acidic medium $(\mathrm{pH}=5)$ the $\beta$-CD caps were loosened, and drugs were released $(88.5 \%$ and $98.7 \%$ for 5-FU and NAP, respectively). To investigate the efficiency of the designed system for the delivery in biological environment, the biocompatibility and cytotoxicity experiments were performed using U87 MG and SKBR3 cancer cells by fluorescence microscopy, flow-cytometry, MTT. apoptotic and CAM assays.
\end{abstract}

\section{Introduction}

The extensive uses of drugs, especially those targeted for the antimicrobial and antineoplastic treatments, lead to various health problems. One of the most important is resistance of surviving cells against the employed drugs, which drastically reduces the efficiency of chemotherapeutics or antibiotics in further treatments. This phenomenon is called multidrug resistance (MDR) $[1,2]$. MDR problem can be reduced by co-delivery approach (or so-called combination therapy) using suitable porous carriers like mesoporous silica nanoparticles (MSN) [3,4]. Such systems can exert simultaneous and synergistic action on more than one critical metabolic pathway and can increase the apoptotic effect throughout the co-delivery of several drugs. It was shown that codelivery of doxorubicin and camptothecin showed great potential for tumor-trigged drug release and for use in the synergistic chemotherapy of tumors like glioblastoma [5]. Liu et al. reported that the silica nanoparticles prepared by co-loading of doxorubicin and paclitaxel, a hydrophilic and a hydrophobic chemotherapeutics, could be internalized efficiently by alveolar cancerous cells and produce an enhanced apoptotic effect in comparison with the single drug model [6].

Co-delivery approach was studied either by co-delivery of two anticancer drugs or in combination of anticancer drug with another therapeutic molecule showing anti-inflammatory, immunologic, antiallergic or anti-angiogenic properties [7]. It was demonstrated, that when doxorubicin (DOX) was loaded with an anti-angiogenic drug Combretastatin A4 (denoted as CA4) the DOX/CA4 loaded silica nanoparticles showed the clear inhibition of tumor growth in vivo although the in vitro apoptotic effect showed similar values as for single drug loading [7].

In the case of antibiotics, combination/co-delivery therapy is used against polymicrobial infections or recalcitrant infections that are not eradicated by standard treatment regimes. Indeed, this combination can broaden the spectrum of antibacterial activity and provide synergistic effects, e.g. if one drug stimulates the uptake of another. This behavior was observed when vancomycin and polymyxin B where encapsulated and delivered using MSN [8]. Loading of both antibiotics had synergistic

\footnotetext{
* Corresponding authors.

E-mail addresses: virginie.hornebecq@univ-amu.fr (V. Hornebecq), vladimir.zelenak@upjs.sk (V. Zeleňák).
} 
effect against Gram-negative bacteria, and the antimicrobial efficacy was higher for MSN loaded with both antibiotics, compared to free antibiotics at the same concentration [8].

In addition to scientific works mentioned above, the co-delivery approach using MSN was also applied in the co-delivery of antitumor drug paclitaxel (PTX) and anti-inflammatory, immunologic and antiallergenic drug, tetrandrine (TET) [9]. It was shown that silica particles containing both PTX and TET suppressed tumor cells growth more efficiently than the delivery of PTX from silica particles alone, or the free PTX alone. Moreover, the nanoparticles loaded with a PTX/TET completely reversed the resistance of human mammary cells used [9].

It is obvious that the use of mesoporous silica particles for targeted drug delivery was intensively studied in recent years [10-13]. The loading and release of drugs from the silica mesopores is a complex process since it depends on many parameters such as the different solubility of guest molecules in the solvent, the different diffusion rates throughout the pores and/or the strength of the interactions between loaded molecules and silica nanoparticles. The first studies of the silica as a drug delivery system focused on dissolution/diffusion mechanism of delivery $[10,11]$. However, at present more sophisticated systems can be prepared, that hamper an undesired (premature) release of loaded compounds and the release can be triggered on demand, using various physical or chemical stimuli [14-19]. Since the mesoporous silica particles can deliver drugs inside the cells [20], such vectored delivery directly into cells, in combination with co-delivery approach and the release on demand, can partially solve the problem of above-mentioned resistance (MDR), by the targeted killing of tumor cells. The first mesoporous silica-based DDS was MCM-41 material [21]. After this discovery, different silicas were tested for drug loading and release and, among them, the SBA-15 silica has been extensively reported since its two-dimensional hexagonal porous structure similar to MCM-41, but larger pore size (5-10 $\mathrm{nm}$ in diameter). The larger pore size makes SBA15 material suitable for loading larger amounts of drugs as well as more bulky drug molecules or even macromolecules [22-26].

Considering the above-mentioned studies, the present work aims to explore the possibility of co-adsorption and co-delivery of two different drugs, an anticancer drug (5-fluorouracil; 5-FU) and an antiinflammatory agent (Naproxen; NAP). In our previous works, we have prepared and described the different mesoporous silica particles, that release drugs either on diffusion principle $[27,28]$ or using external stimulus, e.g. light driven drug release $[29,30]$ or $\mathrm{pH}$ driven drug release [31]. In the latter, the system releasing the drug by decreasing $\mathrm{pH}$ is especially suitable for the delivery of anticancer drugs. In the present paper, we study the co-adsorption and co-release of 5-FU and NAP using MSN system composed of SBA-15 nanoparticles as a carrier, which were modified by $\beta$-cyclodextrin ( $\beta$-CD) as a cap closing the carrier nanopores and preventing the premature release of the drugs. The properties of such carrier, its co-delivery characteristics and biocompatibility were evaluated by different biological assays like MTT, apoptosis and CAM assay or cytotoxicity study.

\section{Experimental section}

All chemicals used in the syntheses were obtained by Sigma-Aldrich and Across Organics companies in the highest purities and used without further purification. Anhydrous solvents were obtained after standard procedures described in the reference [32] and stored over molecular sieves.

\subsection{Synthesis and functionalization of silica $S B A-15$}

SBA-15 silica was prepared by the template synthetic method using a procedure reported by Zhao et al. [33]. Triblock copolymer Pluronic P123 was used as a structure reacting agent and tetraethoxysilane (TEOS) as a silica source. The molar ratio of used reagents was 1 TEOS : $5.9 \mathrm{HCl}: 193 \mathrm{H}_{2} \mathrm{O}: 0.017 \mathrm{P} 123$. The prepared as-synthesized material was further calcined to obtain the final mesoporous SBA-15 material.

The surface functionalization was done by the post-synthetic grafting of SBA-15 using N-[3-(trimethoxysilyl)propyl] aniline (N-ANI) to form amine-functionalized silica matrix. In a typical procedure, $1 \mathrm{~g}$ of preheated SBA-15 (pre-heated to $150{ }^{\circ} \mathrm{C}$ ) was dispersed in anhydrous toluene and mixed with $3 \mathrm{~mL}$ of $\mathrm{N}$-ANI (12.5 mmol). The mixture was refluxed under $\mathrm{N}_{2}$ for $20 \mathrm{~h}$. The obtained product was centrifuged, several times washed with toluene and ethanol, and dried at $40^{\circ} \mathrm{C}$ for 24 h. The resulting product was denoted as SBA-15_N-ANI.

\subsection{Drugs loading}

\subsubsection{Adsorption properties of silica supports}

Antineoplastic agent, 5-Fluorouracil (5-FU) and anti-inflammatory agent Naproxen (NAP) were taken as model drugs to estimate the coadsorption and co-release performance of $\mathrm{pH}$-responsive silica support. Initially, adsorption properties of silica materials SBA-15 and SBA15_N-ANI were studied with 5-FU and NAP separately. Adsorption was performed on both the SBA-15 and SBA-15_N-ANI for comparative purposes.

Drugs were loaded into the supports by the impregnation method using drug solutions of known concentrations. The limiting factor was the solubility of 5-FU, which is sparingly soluble in water. Therefore, the highest possible concentration for $5-\mathrm{FU}$ was set at $6.5 \mathrm{mg} / \mathrm{mL}\left(5.10^{-2}\right.$ M), as already discussed in our previous study [31]. For the adsorption studies, the concentration of naproxen was therefore adjusted also to this value and the highest concentration was the same for both drugs used.

For the construction of adsorption isotherms, the materials SBA-15 and SBA-15_N-ANI (0.02 g) were dispersed in a series of plastic vials containing $2 \mathrm{~mL}$ of aqueous solution of drug in growing initial concentrations of $0.13,0.325,0.65,0.975,1.3,3.25,6.5 \mathrm{mg} / \mathrm{mL}$. Suspensions were stirred at $300 \mathrm{rpm}$ for $24 \mathrm{~h}$ at $37^{\circ} \mathrm{C}$ while the evaporation of water was prevented. The suspensions were then centrifugated at $10000 \mathrm{rpm}$ for $10 \mathrm{~min}$; after centrifugation the supernatants were separated from the solids and the impregnated solids were dried overnight at $40^{\circ} \mathrm{C}$ in an oven. The samples with the 5-FU and NAP drugs separately loaded in SBA-15 and SBA-15_N-ANI were denoted SBA-15_5-FU, SBA-15_NANI_5-FU or SBA-15_NAP, SBA-15_N-ANI_NAP, respectively.

The co-adsorption process followed the same procedure as mentioned above. $0.02 \mathrm{~g}$ of the silica support was dispersed in a solution of drugs mixture in different ratio, 5-FU:NAP 3.5:0.5, 3:1, 2.5:1.5, 2:2, 1.5:2.5, 1:3, 0.5:3.5 (final volume of the solution was $2 \mathrm{~mL}$ ). The initial highest concentration of drug solution was fixed to $5 \cdot 10^{-2} \mathrm{M}$. The subsequent procedure was the same as for simple adsorption. The observed samples were denoted as SBA-15_5-FUN and SBA-15_N-ANI_5-FUN.

Adsorbed amounts of the drugs were determined using UV spectroscopy at $\lambda=266 \mathrm{~nm}$ for 5 -FU and $\lambda=330 \mathrm{~nm}$ for NAP. Before the determination of the concentration of 5-FU and NAP, calibration curves have been established based on solutions with different concentrations of 5-FU and NAP (see Figures S1, S2 in the Supplementary Information). The linearity of the calibration curves was confirmed by the correlation coefficient $r^{2}=0.99996$ for 5-FU and $r^{2}=0.99989$ for NAP. Then, the adsorbed amount of drug, $\mathrm{Q}_{\mathrm{ADS}}$, was calculated considering the difference between the initial concentration and the concentration of drugs in the supernatant, as follows:

$Q_{A D S}=\frac{V\left(C_{i}-C_{e q}\right)}{m}$

where $C_{i}(\mathrm{M})$ is the initial concentration, $C_{e q}(\mathrm{M})$ is the equilibrium concentration after $24 \mathrm{~h}$ at $37^{\circ} \mathrm{C}, V$ is the volume of the drug solution, and $m$ is the mass $(\mathrm{g})$ of adsorbent used.

Microcalorimetric experiments were performed to determine the adsorption enthalpies of drugs on the prepared supports surface. During these experiments, solids (SBA-15 and SBA-15_N-ANI) were maintained 
in water suspension using a stirring system and a stock solution of NAP and $(\mathrm{NAP}+5-\mathrm{FU})$ was added by $10 \mu \mathrm{L}$ aliquots step by step (10 injections). Next, the heat flow peaks were time-integrated and after correction of dilution effects, the integral enthalpies were obtained.

\subsubsection{Capping of loaded SBA-15_N-ANI_5-FUN nanoparticles by $\beta$-CD}

A solutions of 5-FU and NAP were prepared in distilled water at ambient temperature with the concentration of each $6.5 \mathrm{mg} / \mathrm{mL}\left(5.10^{-2}\right.$ $\mathrm{M})$ and then mixed. In the next step $300 \mathrm{mg}$ of the solid SBA-15_N-ANI was added to the drugs mixture solution and stirred at $37{ }^{\circ} \mathrm{C}$ for $24 \mathrm{~h}$ until the equilibrium was achieved. Then, the $\mathrm{pH}$ of the suspension was adjusted to 7.4 and $800 \mathrm{mg}$ of $\beta$-CD was added to the solution. The mixture was stirred overnight. Then, nanoparticles were centrifuged, washed with water, and used in further experiments. At each further step, the $\mathrm{pH}$ of the suspensions was carefully checked, and supernatants were analyzed by UV/Vis spectroscopy. The obtained sample was denoted as SBA-15_N-ANI_5-FUN_ $\beta$-CD.

\subsection{Release of the drugs}

The release of the drugs was checked at selected time intervals: 0.08 h, 0.33 h, 0.66 h, 1 h, 2 h, 3 h, 4 h, 5 h, 6 h and 24 h. During these time intervals, the mixtures were stirred gently at $37{ }^{\circ} \mathrm{C}$ in a tube rotator. In each defined time interval, the suspension was centrifuged and the supernatant was removed and analyzed. The released amounts of 5-FU or NAP from the samples, where they were loaded alone, or co-adsorbed from their mutual mixture 5-FU+NAP were calculated from calibration curves (see Figures S1 and S2 in the Supplementary Information). The 5-FU was recorded at the wavelength of $266 \mathrm{~nm}$ and NAP at $330 \mathrm{~nm}$. The absorbance of 5-FU and NAP at $266 \mathrm{~nm}$ and $330 \mathrm{~nm}$ does not overlay on each other.

\subsubsection{Release experiments from the supports containing single drug}

The release studies of 5-FU and NAP from samples SBA-15_N-ANI_5FU and SBA-15_N-ANI_5-NAP, i.e. when each drug was encapsulated alone, were performed as $\mathrm{pH}$ dependence. For this purpose, the $\mathrm{pH}$ of a saline solution, used as a release medium, was set to $\mathrm{pH}$ equal to 7.4 and 5 .

2.3.2. Release experiments from the supports containing co-adsorbed drugs

To analyze the release of 5-FU and NAP from SBA_15_N-ANI_5-FUN $\beta$-CD, the particles were placed into the cuvette of spectrometer and 2 $\mathrm{mL}$ of saline solution ( $\mathrm{pH} 7.4$ or 5 ) was added carefully.

\subsection{Cell culture preparation}

The cell cultures were cultivated according to the standard propagation protocols [34]. The U87 MG glioma cells (Cells Lines Services, Germany) and SKBR3 human breast carcinoma cells (a gift from prof. Pluckthun laboratory, University of Zurich, Switzerland) were grown in the cell culture medium (high glucose, GlutaMAXTM supplement, pyruvate Dulbecco's modified Eagle medium, D-MEM, Gibco-Invitrogen, Life Technologies Ltd., France) and RPMI 1640 (LM-R1638/500, biosera, France), respectively in the dark at $37{ }^{\circ} \mathrm{C}, 5 \%$ of $\mathrm{CO}_{2}$ and humidified atmosphere. The complete cell culture medium was prepared with $10 \%$ fetal bovine serum (FBS, biosera, France). One day before experiments the cells were seeded into the $35 \mathrm{~mm}$ in diameter Petri dishes or 96-well plates and grown in the complete medium at $\mathrm{pH}=7.3$ or 6.3 . The next day, the aliquots of the 5-FU, NAP, and SBA-15_N-ANI_5-FUN_ $\beta$-CD were administered. The sterile powders of the substances were dissolved in distilled water and sonicated 15 min before administration.

\subsection{Microscopy}

The $24 \mathrm{~h}$ after the administration of 5 -FU (5.7 and $57 \mu \mathrm{g} / \mathrm{mL}$ ), NAP $(114 \mu \mathrm{g} / \mathrm{mL}$ ) and SBA-15_N-ANI_5-FUN_ $\beta$-CD (from 0.2 up to $2 \mathrm{mg} / \mathrm{mL}$ ) the cells seeded in glass coverslip bottom Petri dishes (MatTek, USA) were observed in the bright - field mode with the inverted LSM700 confocal microscope (Zeiss, Germany), equipped with a 20X Fluar (NA $=0.75, \infty$, Zeiss, Germany) and a CCD camera (AxioCam HRm, Zeiss, Germany).

\subsection{Cell viability - MTT assay}

The MTT (3-(4,5-dimethylthiazol-2-yl)-2,5-diphenyltetrazolium bromide, Sigma-Aldrich, Germany) assay was performed 24 and $48 \mathrm{~h}$ after the administration of 5-FU (from 5.7 up to $57 \mu \mathrm{g} / \mathrm{mL}$ ), NAP (from 45.6 up to $114 \mu \mathrm{g} / \mathrm{mL}$ ), and SBA-15_N-ANI_5-FUN_ $\beta$-CD (from 0.2 up to $2 \mathrm{mg} / \mathrm{mL}$ ). Two molar ratios (1:1 and 1:2) of 5-FU:NAP in SBA-15_NANI_5-FUN_ $\beta$-CD were tested. The amount of drugs adsorbed were determined by TGA (see Figure S3 in the Supplementary information) and by solid/liquid adsorption measurements (see Table T1 in the Supplementary Information). The same protocol was kept for MTT-assay [31]. The results were detected in the triplicates. The significance of difference was estimated with the student $t$-test with *p $<0.05$, ** $\mathrm{p}<$ 0.01 and $* * * \mathrm{p}<0.001$.

\subsection{Apoptotic assay}

The cells (treated $48 \mathrm{~h}$ with 5-FU, NAP, and SBA-15_N-ANI_5-FUN $\beta$-CD) were 15 min labelled with the mitochondria potential probe a MitoTracker ${ }^{\mathrm{TM}}$ Orange CMTM/Ros (MTO, $0.2 \mu \mathrm{M}$, ThermoFisherScientific, USA) and an AnnexinV/FITC (FITC Annexin V Apoptosis Detection Kit, BD PharmingenTM, Belgium) to detect phosphatidylserine in the plasma membrane. The cells were detached with the trypsin/ ethylene-diaminetetraacetic acid (Gibco-Invitrogen, Life Technologies Ltd., France), centrifuged at $1200 \mathrm{rpm} / 10 \mathrm{~min}$ and resuspended in 0.5 $\mathrm{mL}$ of phosphate saline buffer (PBS) at $\mathrm{pH}=7.4$. The harvested cells were measured with the flow cytometer (MACSQuant ${ }^{\circledR}$ Analyzer, Miltenyi, Germany) in B1 (525/50 $\mathrm{nm})$ and B3 $(655-730 \mathrm{~nm})$ channel at the excitation $488 \mathrm{~nm}$.

\subsection{CAM assay}

Chorioallantoic membrane (CAM) of the fertilized Japanese quail's (Coturnix japonica) eggs (a breeding colony of IABG SASci) was used for in vivo biocompatibility study. The eggs were kept in an incubator (MIDI BIOS, Czech Republic) at $37{ }^{\circ} \mathrm{C}$ and $50-60 \%$ relative humidity. The eggs were disinfected in a sterile condition with $70 \%$ ethanolic solution at embryonic day 3 (ED3). The eggs were opened and the embryos were placed into the 6-well tissue culture plates and cultivated in $37{ }^{\circ} \mathrm{C}$ humidified incubator (Memmert, Germany) until ED10. The silicon rings were placed on the CAM. The volume of $30 \mu \mathrm{L}$ of the studied solutions was administered inside the ring. The image was detected with a digital camera (Canon EOS 6D II with Canon MP-E 65 mm f/2.8, Japan).

\subsection{Histology}

The treated tissue of the CAM was fixed with $4 \%$ paraformaldehyde (Sigma-Aldrich, Germany) and separated. The paraffin sections with the $5 \mu \mathrm{m}$ thickness were prepared for histopathological analysis to determine the damage of the tissue (hematoxylin (BAMED, Slovakia) and eosin (BAMED, Slovakia) staining). The sections were evaluated with a light microscope Kapa 2000 (Kvant, Slovakia) at 10X magnification, and digital camera Nikon E995 (Japan).

\subsection{Characterization of porous solids with analytical techniques}

Nitrogen sorption measurements were carried out using an ASAP 2020 Micromeritics apparatus at $-196^{\circ} \mathrm{C}$. Before adsorption, samples ( $~ 80-100 \mathrm{mg}$ ) were degassed at $120^{\circ} \mathrm{C}\left(40{ }^{\circ} \mathrm{C}\right.$ for grafted samples and samples containing drug molecules) during $12 \mathrm{~h}$ under the vacuum of 
$2.10^{-3}$ mbar. The specific surface area was determined with BrunauerEmmet-Teller (BET) method, the pore size distribution was calculated from the adsorption branch using the Barrett-Joyner-Halenda (BJH) method [35].

TEM micrographs were obtained using a JEOL 2000FX microscope. Samples were ground and suspended in methanol. The suspension was dropped on a carbon grid and dried in air.

UV-Visible spectroscopy measurements in the liquid phase were performed on a Varian Cary 300 spectrometer in the $200-400 \mathrm{~nm}$ range.

Thermogravimetric (TGA) measurements were carried out with a TGA Q500 apparatus (TA Instruments) using air as a carrier gas. The samples with weight $\sim 5-20 \mathrm{mg}$ were treated from ambient temperature up to $800{ }^{\circ} \mathrm{C}$.

Small-angle X-Ray diffraction measurements were recorded on a Siemens D500R XRD diffractometer using $\mathrm{Cu}$ K $\alpha$ radiation $(\lambda=1.54060$ $\AA$ ) in the $0.5-3^{\circ} 2 \theta$ range with a $0.04^{\circ}$ step associated with a step time of $4 \mathrm{~s}$.

Microcalorimetry experiments were performed on TAM 2277 microcalorimeter.

\section{Results and discussion}

In the present paper, we study the co-adsorption and co-release of 5FU and NAP using MSN system composed of amine grafted SBA-15 material and $\beta$-cyclodextrin $(\beta-C D)$. For the preparation of the functional material, the mesoporous silica SBA-15 was surface modified by grafting procedure, during which silica surface hydroxyl groups reacted with N-[3-(trimethoxysilyl)propyl]aniline (see Scheme 1). During this grafting procedure amine was covalently attached on the silica surface.

This covalently attached amine represents an immobilized stalk molecule covalently attached to silica surface and $\beta$-cyclodextrin represents a mobile cyclic molecule encircling the stalk via non-covalent interactions. The non-covalent interactions between stalk and cyclic molecule $\beta$-CD are therefore crucial for pore blocking effect (see Fig. 1). Such supramolecular nanovalves responsible for opening and closing the pores of the carrier and preventing the premature release of the drugs. When the $\mathrm{pH}$ of the environment is decreased from its initial values $(\sim 7.4)$, the molecules on the silica surface become protonated resulting that binding affinity with cyclodextrin is decreased. As it was already demonstrated the $\beta$-CD caps are thus dispersed around from the stalks and pores are opened [36,37].

Different amines and cyclodextrin molecules have been demonstrated to be an effective supramolecular pore gatekeepers for mesoporous silica materials. For example Meng et al. reported a MSN delivery system based on the $\beta$-CD nanovalves and $\mathrm{N}$-methyl benzimidazole molecules as a stalks, which bind to the $\beta$-CD rings strongly at $\mathrm{pH} 7.4$

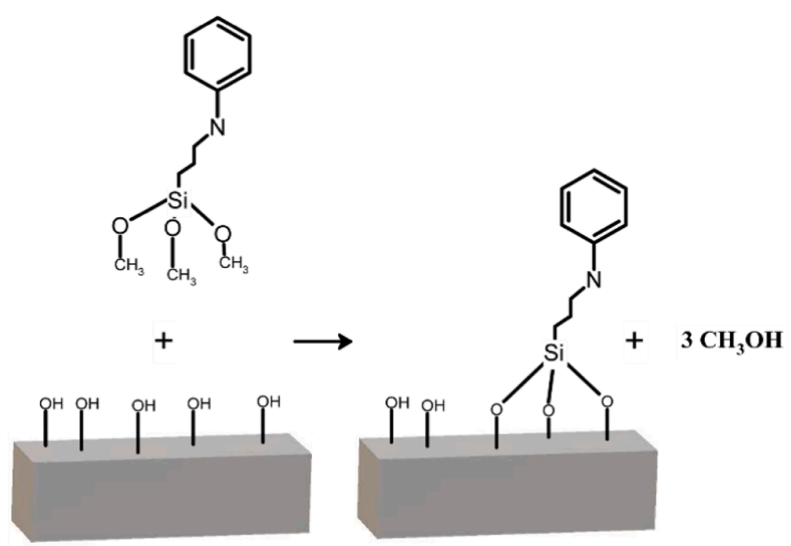

Scheme 1. Grafting of N-[3-(trimethoxysilyl)propyl]aniline on the SBA-15 silica surface. with trapping drug molecules in pores while causing dissociation with the $\beta$-CD caps at $\mathrm{pH}<6$ [38].

The delivery of doxorubicin was tested in the work of Bai et al. who constructed a pH-responsive controlled release system using p-anisidine amine stalks and different $\mathrm{CD}(\alpha$ and $\beta$ ) as the pore caps to regulate the release of drug from silica channels. The authors studied how stalk density and the type of $\mathrm{CD}$ used to affect release behavior. They found that the ability of $\mathrm{CD}$ to produce a better $\mathrm{pH}$-responsive release was in the order $\beta$-CD $>\alpha$-CD [39]. Therefore, based on these results in our work we focused on $\beta$-CD system.

\subsection{Small angle $X$-ray diffraction}

X-ray diffraction patterns of unmodified/modified SBA-15 samples (see Fig. 2) match well with the typical XRD pattern reported for SBA-15 silica. The pattern is associated with a highly ordered, two-dimensional hexagonal mesostructure (p6mm symmetry) $[33,40]$.

The X-ray diffraction pattern of SBA-15 silica is well resolved with a strong diffraction peak at $2 \theta=0.89 \AA$, and two weaker peaks at $2 \theta=$ $1.54 \AA$ and $1.78 \AA$. They can be indexed as (100), (110) and (200) in hexagonal lattice with a $d(100)$ spacing $99.2 \AA$. The $d$-spacing corresponds to the large unit cell parameter $\mathrm{a}_{0}=114.5 \AA$ as calculated according to the Bragg equation for hexagonal symmetry, $\mathrm{a}_{0}=2 \times d_{100} /$ $\sqrt{ }$ 3. The XRD patterns corresponding to SBA-15_N-ANI and SBA-15_NANI_5-FUN samples show only the (100) and (200) diffractions peaks well resolved. The diffraction peak (110) has lower intensity due to surface modification and drugs loading.

\subsection{Nitrogen adsorption/desorption}

To obtain more precise information about the structure and textural properties of prepared samples, $\mathrm{N}_{2}$ adsorption/desorption measurements were performed. The measurements were used to determine the specific surface area, pore volume, and pore size distribution of the samples. The adsorption/desorption isotherms of the studied samples are shown in Fig. 3a. The isotherm of SBA-15 can be considered as a typical IV(a) type according to IUPAC classification, with well-defined H1 hysteresis loop associated with presence of mesopores [41]. The $\mathrm{H} 1$ hysteresis loop confirms open-ended hexagonal cylindrical pore geometry typical for SBA-15 silica material. The steepness of the hysteresis loop in the relative pressures range $\mathrm{p} / \mathrm{p}_{0}=0.6-0.8$ shows on the wellordered structure with narrow pore size distribution. The presence of micropores interconnecting mesoporous channels in the SBA-15 material is reflected by an initial sharp nitrogen uptake at relative pressures below 0.05 . When the surface of SBA-15 is modified with organic ligands and/or the pores are filled with drugs and capped with $\beta$-CDs, the whole isotherm is shifted to lower relative pressures also the nitrogen adsorbed volume is lower. Furthermore, the microporosity as well as the shape of the hysteresis is changed upon modification and loading. The pore size distributions, calculated from the adsorption branches of isotherms are shown in Fig. 3b. Calculated specific surface areas, mesopore volumes and sizes are summarized in Table 1.

The specific surface areas were calculated using the BET method. As expected, the grafting of the N-ANI ligand leads to a decrease in specific surface areas and total pore volumes. Functionalization of SBA-15 by NANI ligand also downshifts the capillary condensation from $\mathrm{p} / \mathrm{p}_{0}=$ $0.63-0.76$ (pure SBA-15) to lower relative pressures $\mathrm{p} / \mathrm{p}_{0}=0.58-0.65$ (SBA-15_N-ANI) reflecting the filling of the pores and decrease in pore size from $6.5 \mathrm{~nm}$ (pure SBA-15) to $5.3 \mathrm{~nm}$ (SBA-15_N-ANI). The adsorption of drugs 5 -FU and NAP and $\beta$-CD capping caused the further decrease in the specific surface area and total pore volumes for SBA15_N-ANI_5-FUN and SBA-15_N-ANI_5-FUN_ $\beta$-CD samples, as it is obvious from Table 1 . 

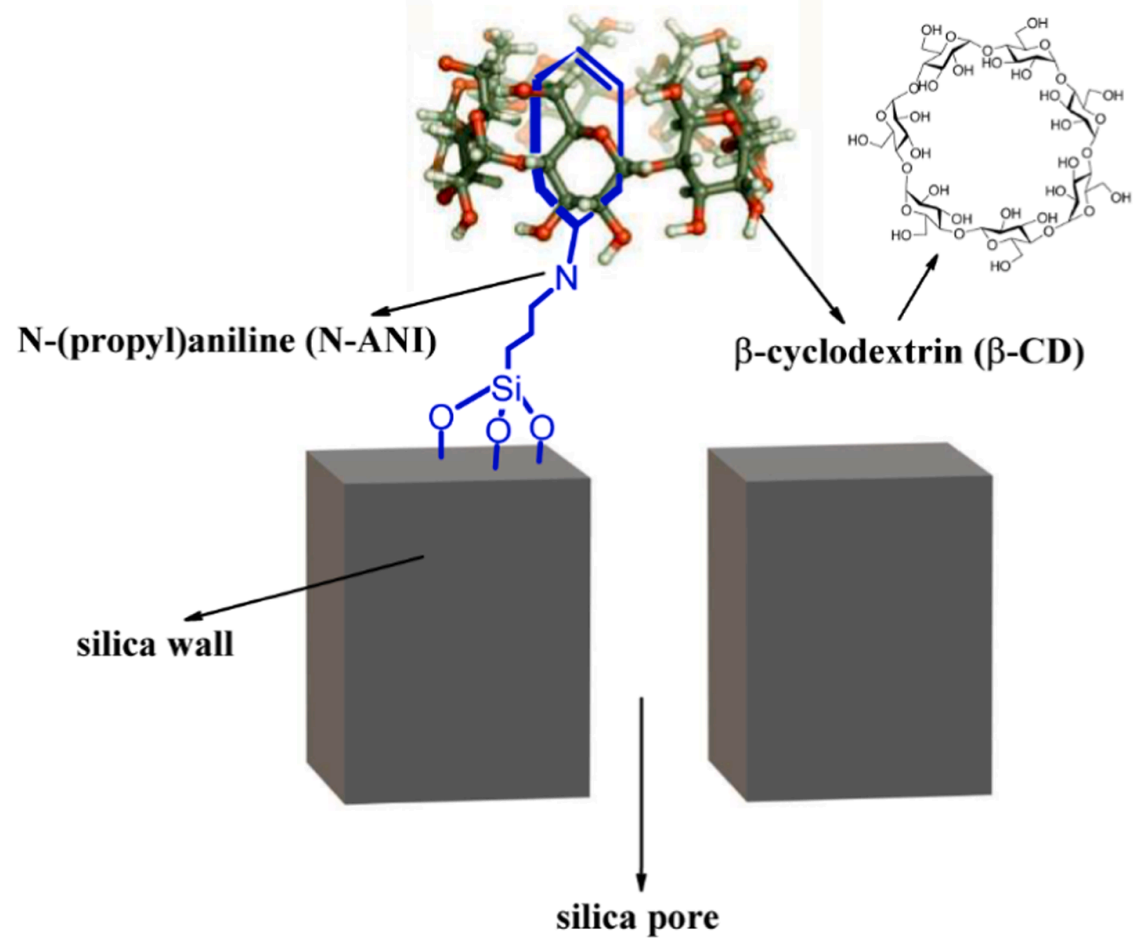

Fig. 1. Representation of non-covalent interaction between N-ANI stalks and cyclic $\beta$-CD molecule.

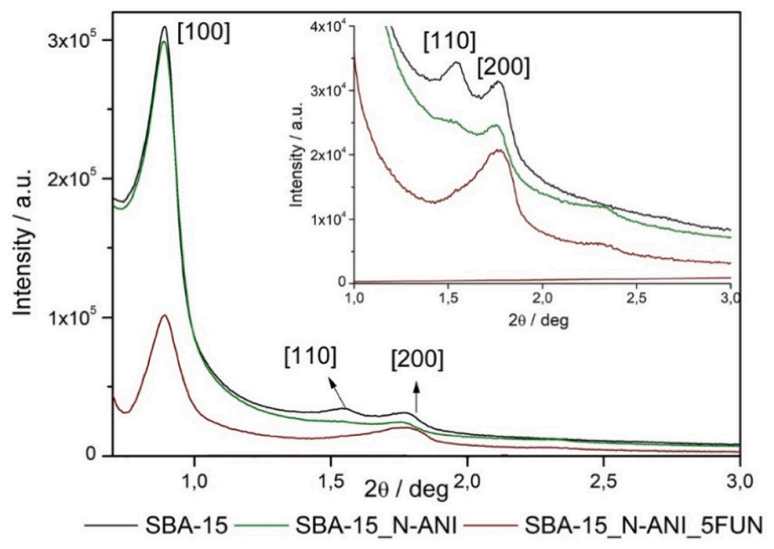

Fig. 2. XRD patterns of SBA-15, SBA-15_N-ANI and SBA-15_N-ANI_5 FUN materials.

\subsection{TEM microscopy}

The images from transmission electron microscopy (TEM) are shown in Fig. S3 in the Supplementary Information. The images show a wellordered hexagonal mesoporous distribution of uniform channels typical for SBA-15 material with 2D hexagonal symmetry. Fig. S3a shows a view obtained with electron beams parallel to the silica channels, while Fig. S3b shows a view perpendicular to the pore direction. The average pore size determined from the TEM images was $6 \mathrm{~nm}$ and the thickness of the wall of the channel was about $2 \mathrm{~nm}$.

\subsection{Thermogravimetric analysis}

Measurements of thermogravimetric analysis (TGA) were performed to determine the amount of N-ANI groups grafted on the surface and the amount of the encapsulated drugs [27]. The results are shown in Fig. S4 in the Supplementary Information. Since the adsorbed moisture and solvents loss occurs in the temperature range $25-150{ }^{\circ} \mathrm{C}$, all TGA curves were normalized with a starting temperature of $150{ }^{\circ} \mathrm{C}$ to evaluate mass loss only due to decomposition of organic ligands and/or drugs. The TGA curve of calcined SBA- 15 shows that the sample is thermally stable, and no significant mass loss is observed in the whole measured range. For SBA-15 sample only a small weight loss $(0.63 \mathrm{wt} \%)$ is observed above $500{ }^{\circ} \mathrm{C}$, corresponding to the silanol groups condensation and the dehydroxylation of the sample. Functionalized mesoporous silica SBA15_N-ANI is thermally stable up to $200{ }^{\circ} \mathrm{C}$. The mass loss, observed above this temperature, corresponds to the thermal decomposition of aromatic amine $\mathrm{N}$-(propyl)aniline (N-ANI) grafted on the surface of SBA15. The total mass loss in the temperature range $200-750{ }^{\circ} \mathrm{C}$ is $21.7 \mathrm{wt}$ $\%$, corresponding to an amount of grafted N-ANI groups equal to 1.03 mmol per $1 \mathrm{~g}$ of SBA-15. The TGA of curve the sample SBA-15_N-ANI_5FUN containing mixture of loaded drugs (5-FU and NAP) is also presented in Fig. S4 in the Supplementary Information (brown curve). The amount of the loaded drugs was calculated from the mass differences observed for SBA-15_N-ANI and SBA-15_N-ANI_5-FUN samples and represents $9.6 \mathrm{wt} \%$, that corresponds to a total mass of $96 \mathrm{mg}$ of 5-FU and NAP per $1 \mathrm{~g}$ of SBA-15_N-ANI solid. Finally, the mass content of $\beta$-CD in the system was also calculated from the SBA-15_N-ANI_5-FUN_ $\beta$-CD TG curve, and a mass of $74.7 \mathrm{mg}$ of $\beta$-CD per $1 \mathrm{~g}$ of silica $\left(0.0658 \mathrm{mmol} . \mathrm{g}^{-1}\right)$ was found. From the total mass loss observed for the sample SBA-15_N-ANI_5-FUN_ $\beta$-CD (Fig. S4, pink curve) the determined ratio of $\mathrm{N}$-ANI ligands and capping ligand $\beta$-CD on the surface of silica was $1: 3$.

3.5. Adsorption and co-adsorption properties of SBA-15 and SBA-15_NANI

Adsorption isotherms in liquid phase were measured to understand the adsorption mechanism of the drugs and to quantify the distribution 


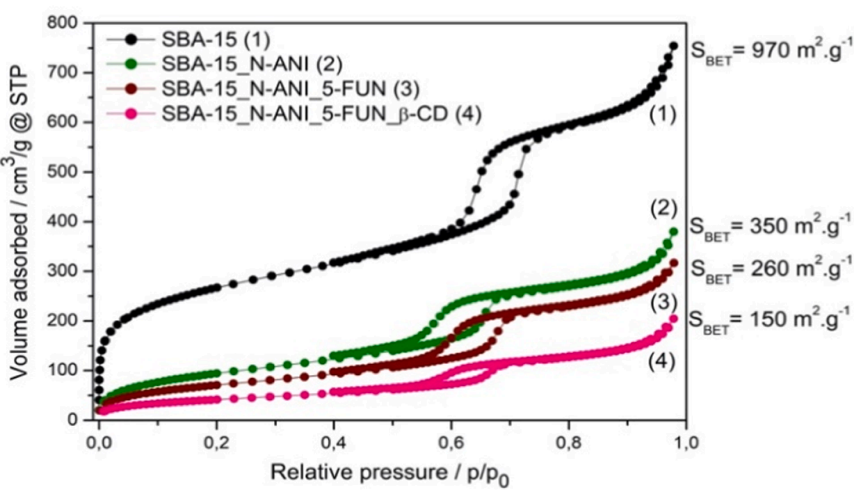

a

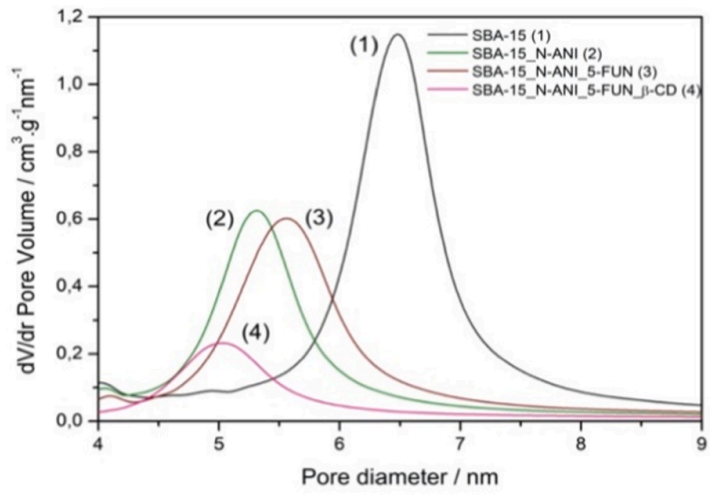

b

Fig. 3. (a) Nitrogen adsorption/desorption isotherms of prepared materials and (b) pore size distributions of prepared samples.

Table 1

Textural properties of the prepared samples (BET surface area, pore volume and pore diameter) determined from $\mathrm{N}_{2}$ adsorption/desorption isotherms.

\begin{tabular}{|c|c|c|c|}
\hline Sample & $\begin{array}{l}\mathrm{S}_{\mathrm{BET}}\left[\mathrm{m}^{2} .\right. \\
\left.\mathrm{g}^{-1}\right]\end{array}$ & $\begin{array}{l}\text { Mesopore volume } \\
{\left[\mathrm{cm}^{3} \cdot \mathrm{g}^{-1}\right]}\end{array}$ & $\begin{array}{l}\text { Mesopore size } \\
{[\mathrm{nm}]}\end{array}$ \\
\hline SBA-15 & 970 & 0.96 & 6.5 \\
\hline SBA-15_N-ANI & 350 & 0.53 & 5.3 \\
\hline $\begin{array}{l}\text { SBA-15_N-ANI_5- } \\
\text { FUN }\end{array}$ & 260 & 0.46 & 5.6 \\
\hline $\begin{array}{l}\text { SBA-15_N-ANI_5- } \\
\text { FUN_ } \beta \text {-CD }\end{array}$ & 150 & 0.20 & 5.0 \\
\hline
\end{tabular}

of the adsorbate between the liquid phase and solid adsorbent at equilibrium.

The drugs 5-FU and NAP were adsorbed in SBA-15 and SBA-15_NANI. First, adsorption isotherms of single drugs were measured. The adsorption isotherms of 5-FU and NAP on both, SBA-15 and SBA-15_NANI porous solids, determined at $25^{\circ} \mathrm{C}$, are presented in Fig. 4. For both drugs, observed adsorption isotherms are quasi-identical. They are nearly linear corresponding to behavior of Henry isotherms for which a linear relation between the adsorbed amount $\left(\mathrm{N}_{\mathrm{ads}}\right)$ and the equilibrium concentration $\left(\mathrm{C}_{\mathrm{eq}}\right)$ is characteristic:

$N_{a d s}=K_{H} \cdot C_{e q}$

where $\mathrm{K}_{\mathrm{H}}$ is the Henry constant.

This behavior is frequently observed at low surface coverage when

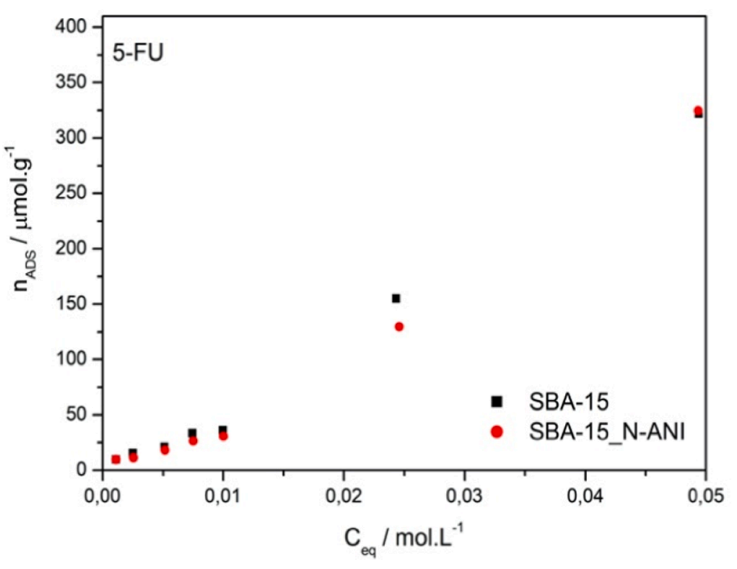

a the system is far away from saturation and the Henry constant traduces the affinity between the surface and the molecule. Value of Henry constant corresponds to:

$K_{H}=\lim _{C_{e q} \rightarrow 0} \frac{d N_{a d s}}{d C_{e q}}$

Each isotherm was fitted with a Henry-type isotherm (correlation coefficients $R^{2}$ were > to 0.98 ) and determined Henry constants are reported in Table 2. As can be seen, whatever the drug and the solid, the values of Henry constant are weak suggesting a weak interaction between drugs and solids. Furthermore, the slope observed in the case of NAP is half compared to the one of 5-FU, evidencing a lower affinity of

Table 2

Adsorption properties of SBA-15 and SBA-15_N-ANI for 5-fluorouracil (5-FU) and naproxen (NAP), when each drug was adsorbed alone.

\begin{tabular}{|c|c|c|c|c|}
\hline Sample & $\begin{array}{l}\mathrm{K}_{\mathrm{H}} \\
(\mathrm{x} 1000)\end{array}$ & $\begin{array}{l}\mathrm{n}_{\mathrm{ADS}}[\mu \mathrm{mol} . \\
\left.\mathrm{g}^{-1}\right]\end{array}$ & $\begin{array}{l}\mathrm{n}_{\mathrm{ADS}}[\mu \mathrm{mol} . \\
\left.\mathrm{m}^{-2}\right]\end{array}$ & $\begin{array}{l}\mathrm{m}_{\mathrm{ADS}}[\mathrm{mg} . \\
\left.\mathrm{g}^{-1}\right]\end{array}$ \\
\hline SBA-15 +5 FU & $\begin{array}{l}6.35 \pm \\
0.22\end{array}$ & 322 & 0.33 & 41.9 \\
\hline $\begin{array}{l}\text { SBA-15_N-ANI + } \\
\text { 5FU }\end{array}$ & $\begin{array}{l}6.14 \pm \\
0.33\end{array}$ & 325 & 0.93 & 42.2 \\
\hline SBA-15 + NAP & $\begin{array}{l}3.20 \pm \\
0.16\end{array}$ & 125 & 0.13 & 31.6 \\
\hline $\begin{array}{l}\text { SBA-15_N-ANI + } \\
\text { NAP }\end{array}$ & $\begin{array}{l}3.25 \pm \\
0.11\end{array}$ & 145 & 0.41 & 36.2 \\
\hline
\end{tabular}

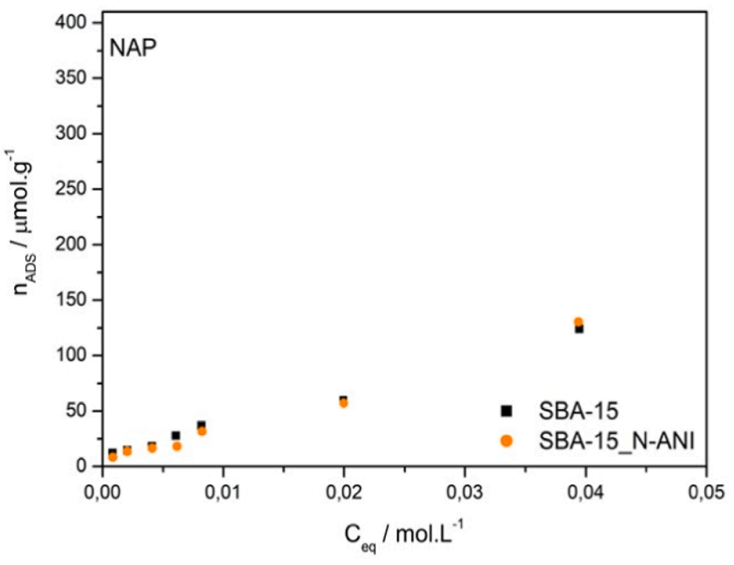

b

Fig. 4. Adsorption isotherms of 5-FU (a) and NAP (b) on SBA-15 and SBA-15_N-ANI solids. 
NAP towards both solids. As it can be seen from Table 2, the adsorbed maximum of $325 \mu \mathrm{mol} \cdot \mathrm{g}^{-1}\left(42 \mathrm{mg} \cdot \mathrm{g}^{-1}\right)$ was found for 5-FU and nearly half for NAP, $145 \mu \mathrm{mol} \cdot \mathrm{g}^{-1}\left(36 \mathrm{mg} \cdot \mathrm{g}^{-1}\right)$.

When 5-FU and NAP drugs are co-adsorbed, the adsorption isotherms are also found to be linear (see Fig. 5) like in the case of drugs alone. Nevertheless, during the co-adsorption a difference is observed in the case of 5-FU as isotherms determined on SBA-15 and SBA-15_N-ANI solids for 5-FU do not superimpose, and the latter is shifted to higher adsorbed amounts (see Fig. 5). For NAP, both isotherms superimpose. Therefore, SBA-15_N-ANI silica has a higher loading capacity of drugs than pure SBA-15 silica, although SBA-15 has a higher specific surface area $\left(970 \mathrm{~m}^{2} \cdot \mathrm{g}^{-1}\right)$ compared to SBA-15_N-ANI $\left(350 \mathrm{~m}^{2} \cdot \mathrm{g}^{-1}\right)$. The determined Henry constants and adsorbed amounts during the coadsorption are reported in Table 3.

Furthermore, in the case of co-adsorption, the slope of the NAP isotherm is double compared to the one of 5-FU (see Fig. 5 and the values of Henry constants in Table 3), evidencing a higher affinity of NAP towards both solids. The maximum adsorbed amounts for both drugs and both solids are reported in different units in Table 3. A maximal adsorbed amount $150 \mu \mathrm{mol} \cdot \mathrm{g}^{-1}\left(20 \mathrm{mg} \cdot \mathrm{g}^{-1}\right)$ was found for $5-\mathrm{FU}$ and higher, $250 \mu \mathrm{mol} \cdot \mathrm{g}^{-1}\left(62 \mathrm{mg} \cdot \mathrm{g}^{-1}\right)$, was found for NAP. Totally 82 $\mathrm{mg} \cdot \mathrm{g}^{-1}$ of drugs was adsorbed and this maximum agrees with the total adsorbed mass close to $96 \mathrm{mg}$, determined for 5-FU+NAP using TGA experiments. All these results suggest a difference in the adsorption properties of NAP when the drug is adsorbed alone or mixed with 5-FU.

To clearly evidence this difference, isotherms determined for SBA15_N-ANI for each drug adsorbed alone and in a mutual mixture are presented in Fig. S5 in the Supplementary Information. As it is clearly shown, there are no differences in adsorption properties for 5-FU drug alone or in mixture; both isotherms, for single 5-FU and in a mixture are very similar. For NAP, the amount of drug adsorbed when it is mixed with 5-FU is almost three times larger than when it is adsorbed alone (see Fig. S5 in the Supplementary Information). The samples SBA-15_NANI has a negative surface charge of $-82 \mathrm{mV}$ at $\mathrm{pH} 7.4$, as it was reported in our previous work [31]. 5-FU has NH groups which are not deprotonated at $\mathrm{pH} 7.4(\mathrm{pKa}(5-\mathrm{FU})=8.02)$. On the contrary, NAP (the pKa $(\mathrm{NAP})=4.15$ ) has a polar carboxylate group so we assume that the adsorption of both drugs is governed by electrostatic interactions and hydrogen bonding with negatively charged particles.

The maximal amounts of the drugs adsorbed on the SBA-15_N-ANI_5FUN_ $\beta$-CD sample, which was prepared for biological tests, were 224 $\mu \mathrm{mol} \cdot \mathrm{g}^{-1}\left(29 \mathrm{mg} \cdot \mathrm{g}^{-1}\right)$ and $361 \mu \mathrm{mol} \cdot \mathrm{g}^{-1}\left(91 \mathrm{mg} \cdot \mathrm{g}^{-1}\right)$ for 5 -FU and NAP, respectively. These maxima agree with the total mass of $126 \mathrm{mg}$, determined for 5-FU+NAP using TGA experiments (see Figure S6 in

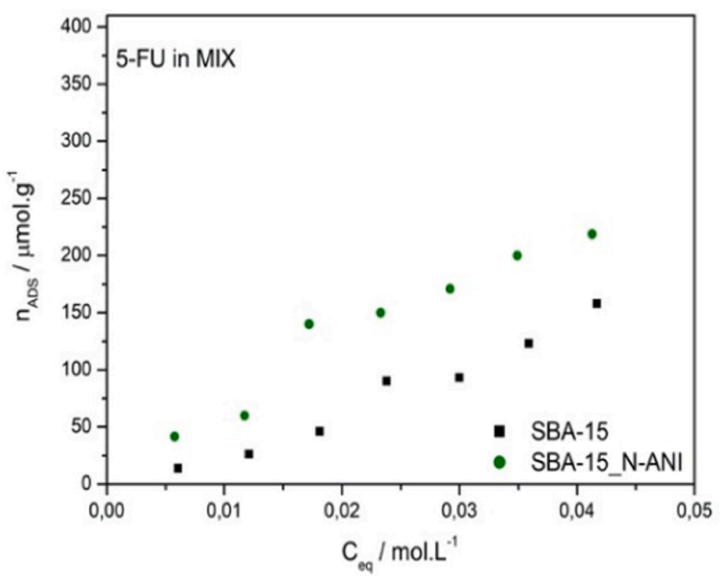

$\mathbf{a}$
Table 3

Co-adsorption properties of drugs 5-fluorouracil (5-FU) and naproxen (NAP) on SBA-15 and SBA-15_N-ANI solids.

\begin{tabular}{|c|c|c|c|c|}
\hline Sample & $\mathrm{K}_{\mathrm{H}}(\mathrm{x} 1000)$ & $\begin{array}{l}\mathrm{n}_{\mathrm{ADS}}[\mu \mathrm{mol} . \\
\left.\mathrm{g}^{-1}\right]\end{array}$ & $\begin{array}{l}\mathrm{n}_{\mathrm{ADS}}[\mu \mathrm{mol} . \\
\left.\mathrm{m}^{-2}\right]\end{array}$ & $\begin{array}{l}\mathrm{m}_{\mathrm{ADS}}[\mathrm{mg} . \\
\left.\mathrm{g}^{-1}\right]\end{array}$ \\
\hline $\begin{array}{l}\text { SBA-15 }+5 \text {-FU in } \\
\text { mix }\end{array}$ & $\begin{array}{l}3.43 \pm \\
0.16\end{array}$ & 90 & 0.09 & 11.7 \\
\hline $\begin{array}{l}\text { SBA-15_N-ANI + 5- } \\
\text { FU in mix }\end{array}$ & $\begin{array}{l}5.82 \pm \\
0.27\end{array}$ & 150 & 0.43 & 19.6 \\
\hline $\begin{array}{l}\text { SBA-15 + NAP in } \\
\text { mixture }\end{array}$ & $\begin{array}{l}10.79 \pm \\
0.36\end{array}$ & 230 & 0.23 & 57.1 \\
\hline $\begin{array}{l}\text { SBA-15_N-ANI + } \\
\text { NAP in mix }\end{array}$ & $\begin{array}{l}11.42 \pm \\
0.27\end{array}$ & 250 & 0.71 & 62.5 \\
\hline
\end{tabular}

Supplementary information). The maximal amounts of both drugs adsorbed alone and from the mixture in different molar ratios are reported in Table ST1 in the Supplementary information.

To complete the study of adsorption properties, the microcalorimetric measurements were performed for the adsorption of NAP on SBA15_N-ANI, as a single drug and as a mixture with 5-FU. The corresponding integral displacement enthalpies are presented in Fig. 6. The overlay of the adsorption enthalpies versus the NAP adsorbed amount

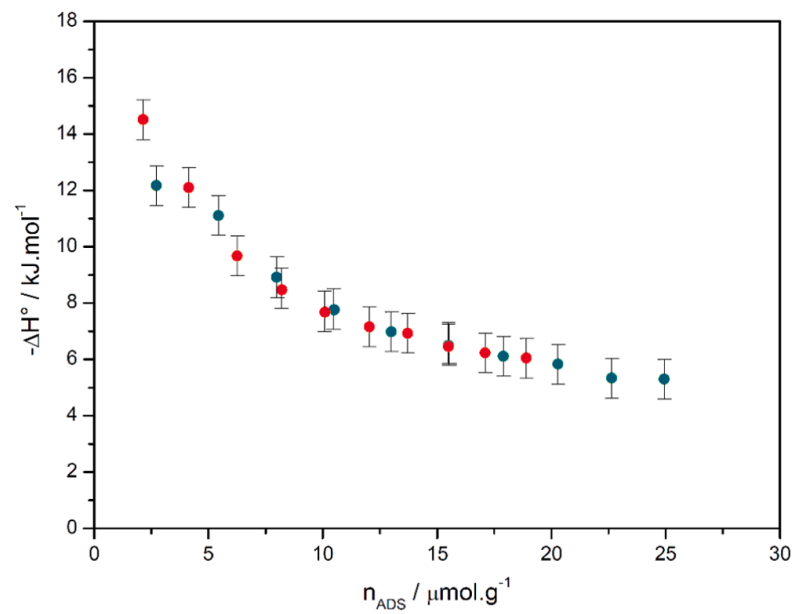

Fig. 6. Evolution of integral displacement enthalpies of NAP adsorbed on SBA15_N-ANI, as a single drug (green dots) and as a mixture with 5-FU (yellow dots).

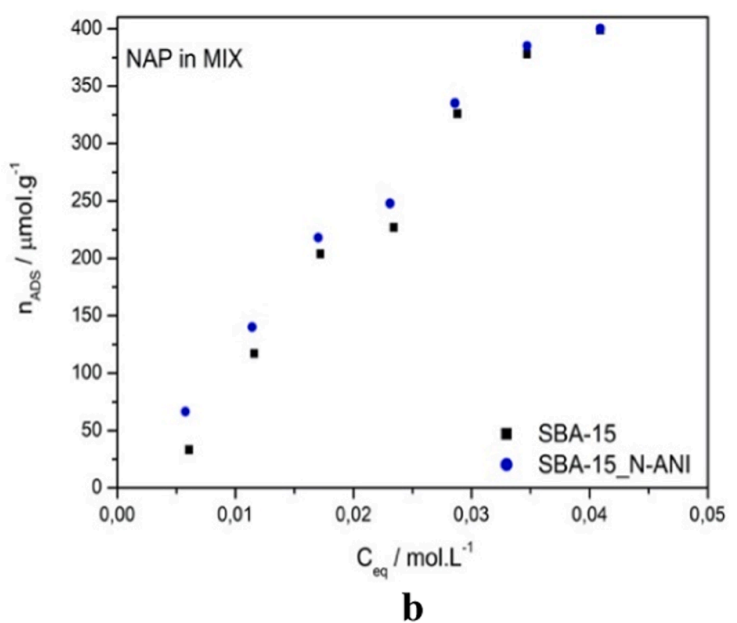

Fig. 5. Adsorption isotherms of co-loaded drugs 5-FU (a) and NAP (b) on SBA-15 and SBA-15_N-ANI. 
exhibits the same behavior: at very low coverage, the enthalpies are close to $-15 \mathrm{~kJ} \cdot \mathrm{mol}^{-1}$, then decrease monotonically with the NAP adsorbed amount until reaching an asymptotical value about -5 $\mathrm{kJ} \cdot \mathrm{mol}^{-1}$. These values of enthalpies can be related to the weak affinity observed between NAP and the surface of SBA-15_N-ANI and are usually met in the case of weak electrostatic interactions. Considering the evolution of enthalpies versus the coverage, two interpretations can be done. First, there is a succession of sites saturated step by step from the highest energy to the lowest. Moreover, the identical shape of enthalpies evolution for a single drug NAP (green dots) and in a mixture with 5-FU (yellow dots) means that the NAP adsorption sites are not dependent on the 5-FU presence, in this range of coverage. Furthermore, NAP and 5FU molecules are not in competition regarding their sites of adsorption.

\subsection{Release performance of 5-Fluorouracil and Naproxen}

Drugs release studies were performed in two different media, in simulated body fluid $(\mathrm{pH}=7.4)$ and slightly acidic medium $(\mathrm{pH}=5)$ simulating the $\mathrm{pH}$ of tumor affected area. The released amounts of 5-FU and NAP from SBA-15_N-ANI_5-FUN_ $\beta$-CD sample at different time intervals $(0.08 \mathrm{~h}, 0.33 \mathrm{~h}, 0.66 \mathrm{~h}, 1 \mathrm{~h}, 2 \mathrm{~h}, 3 \mathrm{~h}, 4 \mathrm{~h}, 5 \mathrm{~h}, 6 \mathrm{~h}$ and $24 \mathrm{~h})$ were investigated using UV spectroscopy. The 5-FU and NAP concentrations during the release studies were determined using the absorbance at 266 $\mathrm{nm}$ for 5-FU and $330 \mathrm{~nm}$ for NAP. The absorbance of 5-FU at $266 \mathrm{~nm}$ and NAP at $330 \mathrm{~nm}$ does not overlay on each other. The calibration curves for 5-FU and NAP were obtained from the UV spectra of drug standards and are shown in Fig. S1 and S2 in the Supplementary Information. The total amount of drugs loaded in SBA-15_N-ANI_5-FUN_ $\beta$-CD sample was established from the adsorption isotherms. The loaded amount was 20 $\mathrm{mg}$ of 5 -FU per $1 \mathrm{~g}$ of silica $\left(0.15 \mathrm{mmol} \cdot \mathrm{g}^{-1}\right)$ and $62 \mathrm{mg}$ of NAP $(0.248$ $\mathrm{mmol} \cdot \mathrm{g}^{-1}$ ) per $1 \mathrm{~g}$ of solid. This result was also confirmed by TGA measurements. These amounts were taken as $100 \%$ in the release studies and used to calculate the percentage of the released amount in the respective time intervals. From the UV spectroscopy results the curves of the time dependencies of the released amounts of 5-FU and NAP from SBA-15_N-ANI_5-FUN_ $\beta$-CD were constructed. The release curves were determined at $\mathrm{pH}=5$, i.e. in the open pore configuration and, at $\mathrm{pH}=$ 7.4 , i.e. in the configuration when pores of the particles are capped by $\beta$-CD. The results are presented in Fig. 7.

As it can be seen from Fig. 7, at $\mathrm{pH}=5$, a significant part of the drugs was released in the first $6 \mathrm{~h}$, when the release of $68 \%$ of 5-FU (Fig. 7a) and $87 \%$ of NAP (Fig. $7 \mathrm{~b}$ ) was observed. In the next $18 \mathrm{~h}$, the sustained release of drugs continued at a much slower rate and additional $20.5 \%$ of

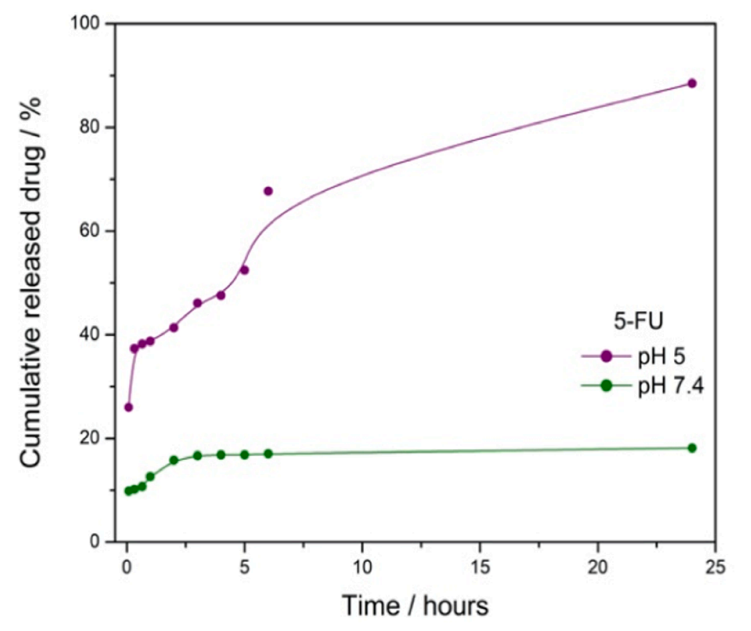

a
5 -FU and $11.7 \%$ of NAP were released. In total, $88.5 \%$ of 5 -FU and $98.7 \%$ of NAP was released in $24 \mathrm{~h}$.

It is obvious that the release performance of the investigated drug delivery system is dependent on the $\mathrm{pH}$. Substantial differences in release profiles at $\mathrm{pH}=7.4$, when the pores of the carrier are blocked by $\beta$-CD, were observed for both drugs, in comparison with the profiles at $\mathrm{pH}=5$. Indeed, there is no significant release at $\mathrm{pH} 7.4$ and only a release of $16 \%$ of 5 -FU and $20 \%$ of NAP in the initial $3 \mathrm{~h}$ was observed. This release could be explained by the fact that not all pores were capped properly by $\beta$-CD molecules. This hypothesis is also in agreement with $\mathrm{N}_{2}$ adsorption/desorption measurements, where some mesoporosity was still observed after $\beta$-CD capping. However, no release of drugs was observed after these $3 \mathrm{~h}$, which leads to the conclusion that supramolecular interaction of the couple N-ANI/ $\beta$-CD is efficient, and this couple may serve as a tight gatekeeper.

To investigate the effect of co-existence of two drugs on the release process, the release profiles of single drugs were also measured. Fig. 8 shows the release profiles of 5-FU (see Fig. 8a) and NAP (see Fig. 8b), at $\mathrm{pH} 5$, when they were released as single drugs (black curves) or in their mixture (5-FU - red curve, NAP - orange curve).

The release profile of 5-FU as a single drug (Fig. 8a, black curve) shows gradual drug release of $45 \%$ in $6 \mathrm{~h}$ and $84 \%$ of 5 -FU in total after $24 \mathrm{~h}$. When 5-FU was mixed with naproxen, (Fig. 8a, red curve), $68 \%$ of 5 -FU was released after $6 \mathrm{~h}$, while $89 \%$ of 5-FU released in total after 24 $h$. It can be seen, that during the same time interval, especially in the first $6 \mathrm{~h}$, a larger amount of 5-FU was released from the system containing a mixture of drugs (even though the starting concentration was two times lower $5.10^{-2} \mathrm{M}$ and $2.5 .10^{-2} \mathrm{M}$ for the release of single 5FU in the mixture, respectively).

The release profile of NAP as a single drug (Fig. 8b, black curve) at $\mathrm{pH}=5$ shows an initial burst of almost $40 \%$ of NAP during the first hour and almost no drug release afterward. The release profile of NAP from the system containing a mixture of drugs (Fig. 8b, orange curve) shows a gradual release of $98.7 \%$ of NAP within $24 \mathrm{~h}$ with a faster release rate.

To sum up, the experiments showed that, while at physiological $\mathrm{pH}$ 7.4 , the prepared drug delivery system is tight enough and only releases $16 \%$ of 5 -FU and $20 \%$ of NAP. When pH decreases to 5 , the pores of the system open and released amounts of drugs are close the maximum adsorbed ones, i.e. $89 \%$ of $5-\mathrm{FU}$ and $98.7 \%$ of NAP.

\subsection{Release kinetics}

Drug release is a phenomenon controlled by diffusion or dissolution

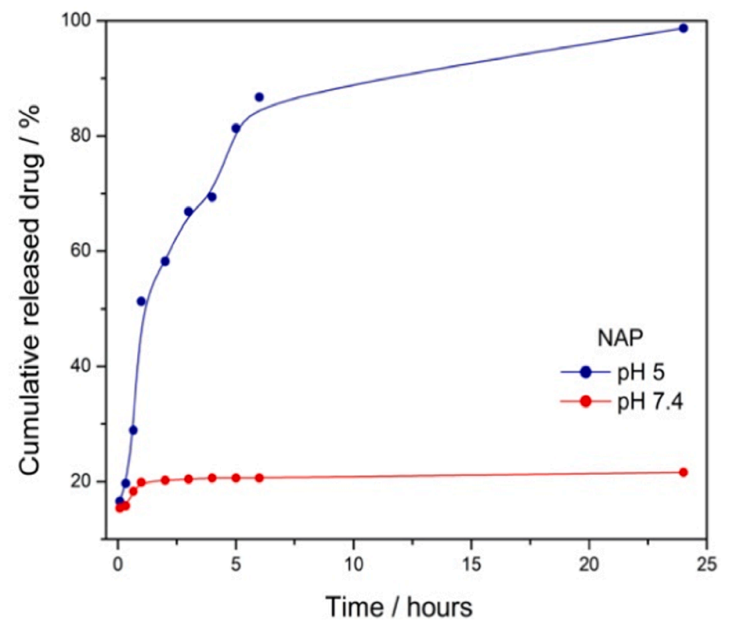

b

Fig. 7. Release profiles of a) 5-FU and b) NAP from solid SBA-15_N-ANI_5-FU_ $\beta$-CD at different two different pH (5 and 7.4). 


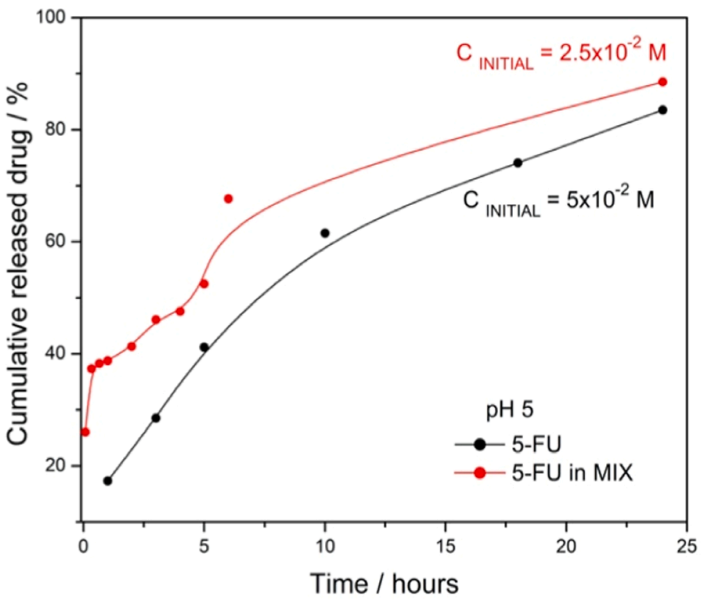

a

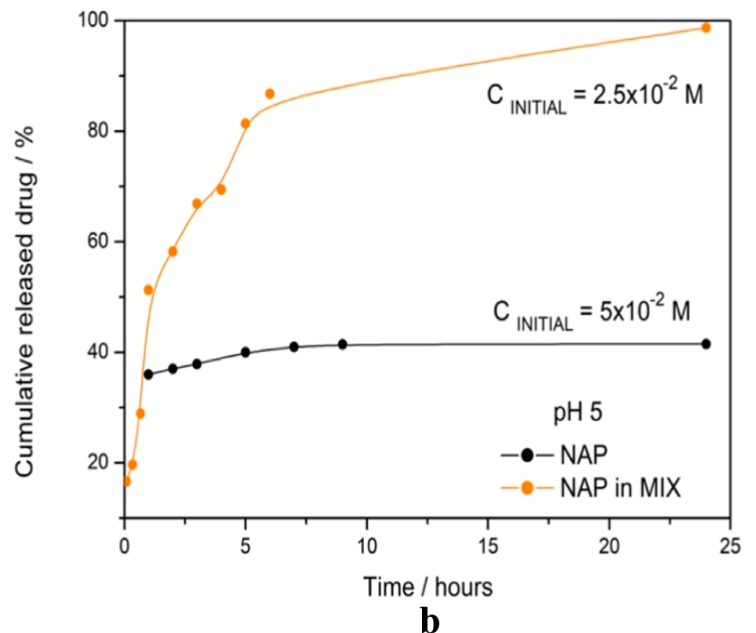

b

Fig. 8. Release profiles of 5-FU (a) and NAP (b) at pH 5 performed in their free form and the mixture. The profiles obtained during the release of single drugs are shown as black curves and profiles obtained during the release in their mixture are shown as red curve (5-FU) and orange curve (NAP).

processes or both factors and in the previous studies, the drug release from porous silica matrices was described as a diffusion-controlled process $[27,42-45]$. To study the mechanism of the 5-FU and NAP release from SBA-15_N-ANI_5-FUN_ $\beta$-CD, drugs release profiles were first fitted with a Higuchi model. The Higuchi square root of time model has commonly been used for modeling diffusion-controlled processes of drug release. The linear regression analysis of the data was performed and determined correlation coefficients $\left(r^{2}\right)$ and rate constants $(k)$ are listed in Table ST2 in the Supplementary Information. As correlation coefficients obtained from the regression analysis for data over the full release time duration were far from one (see Table ST2), it was understood that the release of the drugs should involve several steps. The release of drug is often a two-stage process: a fast release in the initial stage followed by a second stage with a slower release rate. Various types of carriers like microspheres, mesoporous materials, and nanoparticles exhibit different stages of drug release $[46,47]$. For example, the release of vancomycin from silica microspheres shows three stages of drug release, a first delay phase, a second release phase, followed by a third stage with a slower release rate [48]. For this reason, the release profiles of 5-FU and NAP were divided into several stages selected on the criterion of the proximity of the fitting correlation coefficients to one. In this way, the experimental data were divided into three regions for 5-FU (0-0.3 h; 0.3-5 h; 5-24 h) and into two regions for NAP (0-5 h; 5-24 h) and independently regressed with the Higuchi model. The modeling of the first and second stages of both 5-FU and NAP release from SBA-15_NANI_5-FUN_ $\beta$-CD showed a perfect fit with the Higuchi model, as correlation coefficients lie in the 0.94-0.96 range. It means drugs were released by a diffusion-controlled manner. The regression analyses also revealed that the "best fit" is for 5-FU, lower for the third stage than the two first stage. This observation agrees with the literature reporting that significant deviations are possible above $50 \%$ release and that the "best fit" of diffusion-controlled processes is generally better for the modeling of the initial stage of release than for the modeling of the terminal stage $[49,50]$.

To verify the conclusion drawn from the Higuchi analysis dealing with drugs transport mechanisms, the Korsmeyer-Peppas model was also tested with the experimental data. The obtained parameters are listed in Table ST3 in the Supplementary Information. For the first and second stages of 5-FU release, the correlation coefficients were equal to 1 and 0.9363 , respectively and for the first stage of NAP release, $r^{2}=0.9537$. Obtained values evidence, for both drugs, a good fitting between the model and experimental data. Furthermore, the diffusion exponents $(n)$ values that are inferior to $\leq 0.45$ suggest the domination of Fickian diffusion. Thus, the Korsmeyer-Peppas fitting confirms the diffusioncontrolled mechanism identified by the Higuchi analysis.

\subsection{Cytotoxicity of SBA-15_N-ANI loaded with 5-Fluorouracil and Naproxen}

Two different cancer cell lines were used to test the silica-based delivery system: U87 MG and SKBR3 cells. U87 MG cells being larger than SKBR3 ones are more suitable for imaging. SKBR3 cells were used in a flow-cytometric study. A drug resistance can be developed in both selected lines [51,52].

As it was reported recently, SBA-15_N-ANI_5-FU_ $\beta$-CD drug delivery system induced cytotoxic stress in mitochondria and lysosomes of U87 MG cells [31]. For this reason, the cytotoxicity of SBA-15_N-ANI_5FUN_ $\beta$-CD was first assessed in U87 MG cells. The representative brightfield images of U87 MG cells incubated with 5-FU and SBA-15_N-ANI_5FUN_ $\beta$-CD for $24 \mathrm{~h}$ are demonstrated in Fig. 9. The morphology of the cells in the presence and absence of 5-FU was not changed at the studied concentrations. SBA-15_N-ANI_5-FUN_ $\beta$-CD (with 5-FU:NAP at molar ratio 1:1) particles were observed in the same area as the cells (dark particles in Fig. 9a). However, some fragments of the cells surrounded by SBA-15_N-ANI_5-FUN_ $\beta$-CD were detected. Administration of $2 \mathrm{mg} / \mathrm{mL}$ of SBA-15_N-ANI_5-FUN_ $\beta$-CD resulted in relatively large cluster formation.

The viability of U87 MG cells was evaluated by MTT assay at 24 and $48 \mathrm{~h}$ after the administration of 5-FU and NAP loaded SBA-15_N-ANI_5FUN_ $\beta$-CD. The possible synergism of free 5 -FU and NAP was tested as well. First, the solution with the concentration ratios of free drugs 5-FU: NAP 5:1, 1:1, 1:2, 1:4 and 1:20 were applied. The application of 5-FU by 5 -FU loaded SBA-15_N-ANI_5-FUN_ $\beta$-CD significantly increased the formazan production in U87 MG cells detected $24 \mathrm{~h}$ after administration. We have not detected a significant difference in cells treated with 5-FU alone, its combinations with NAP, and with NAP alone. The significant difference of formazan production was observed in cells incubated with SBA-15_N-ANI_5-FUN_ $\beta$-CD at 5-FU:NAP molar ratios 1:1 and 1:2. These significances were found between free 5-FU+NAP and SBA-15_N-ANI_5FUN_ $\beta$-CD, and between both ratios as well. However, the level of formazan production in control and cells incubated in the presence of SBA15_N-ANI_5-FUN_ $\beta$-CD was not significantly different. It looks like SBA15_N-ANI_5-FUN_B-CD formulation protects the release of 5-FU and NAP from the SBA-15_N-ANI_ $\beta$-CD towards the cells. Later, $48 \mathrm{~h}$ of treatment with free 5-FU+NAP (5:1 and 1:4), and SBA-15_N-ANI_5-FUN_ $\beta$-CD (1:2), the viability (related to formazan production) of U87 MG cells was 

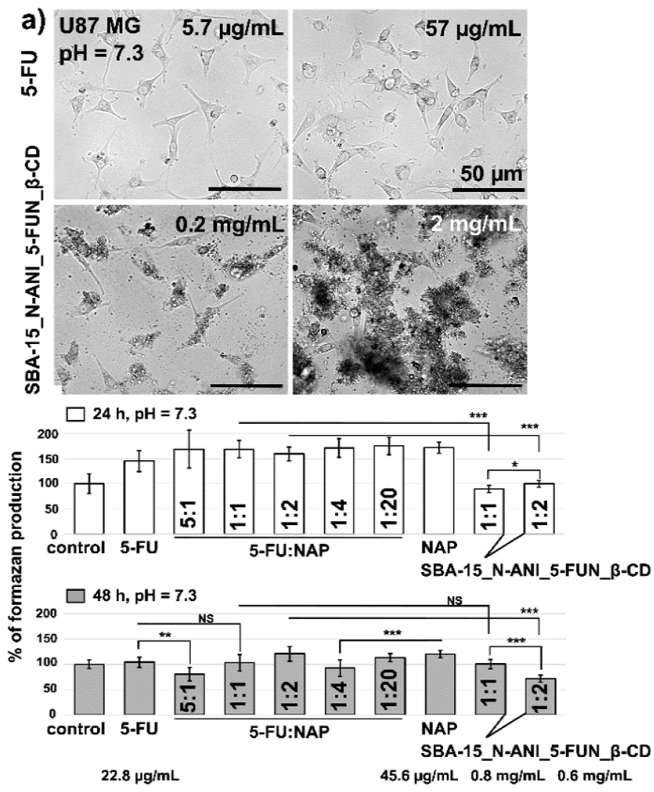

b)
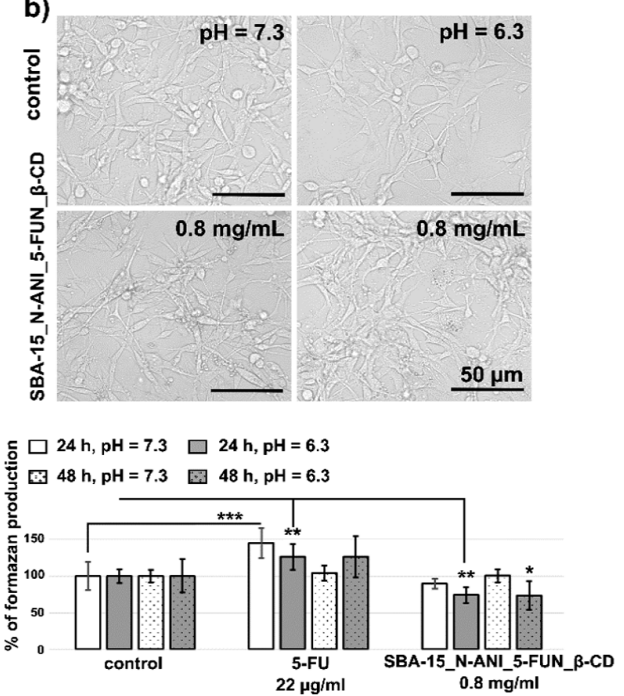

Fig. 9. Representative bright-field microscopic images of U87 MG cells in the absence and presence of 5-FU and SBA-15_N-ANI_5-FUN_ $\beta$-CD. The images were collected $24 \mathrm{~h}$ post-administration at $\mathrm{pH}=7.3$ (a) and 6.3 (b). The MTT assays were performed in cells 24 and $48 \mathrm{~h}$ incubated with 5-FU, NAP, the combination of 5FU + NAP and SBA-15_N-ANI_5-FUN_ $\beta$-CD at different concentration ratios at $\mathrm{pH}=7.3$ (a) and 6.3 (b). The histograms represent the average values of at least three independent experiments and the error bars represent standard deviations from these values. The level of significance was evaluated by the Student $t$-test with the * $\mathrm{p}$ $<0.05, * * \mathrm{p}<0.01$ and $* * * \mathrm{p}<0.001$.

significantly inhibited. It can be seen from these results that the synergistic effect of 5-FU and NAP is concentration depended. It should be noted that the concentration of the 5-FU was constant at 5:1, 1:1 and 1:2, and the NAP concentration was constant at 1:2, 1:4 and 1:20. Importantly, cell viability at SBA-15_N-ANI_5-FUN_ $\beta$-CD (1:2) was significantly different from the control, free 5-FU+NAP (1:2) and SBA-15_NANI_5-FUN_ $\beta$-CD (1:1). These results suggest that SBA-15_N-ANI_5FUN_ $\beta$-CD $(1: 2)$ delivers more effectively 5 -FU into the cells with the synergistic effect induced by NAP.

The synergistic effect of 5-FU co-administered with another anticancer active molecule was demonstrated in hepatocellular carcinoma and colon cancer cells [53,54]. The application of both molecules resulted in apoptosis, an increase of reactive oxygen species production, and dissipation of mitochondrial membrane potential. Moreover, mesoporous silica nanoparticles were previously demonstrated to be able to deliver drugs with high loading capacity and increase the cytotoxicity of the system based on paclitaxel, tetrandrine, 5-FU, coumarin, p53 gene, quercetin, and doxorubicin [9,55-57]. In our study, we aimed to increase the cytotoxicity of 5-FU at low acidic $\mathrm{pH}$.

The effect of the cell culture medium $\mathrm{pH}$ on the cytotoxicity of SBA15_N-ANI_5-FUN_ $\beta$-CD was tested in U87 MG cells. The conditions were maintained at $\mathrm{pH}=6.3$. The representative bright-field images of $\mathrm{U} 87$ MG cells in the presence and absence of SBA-15_N-ANI_5-FUN_B-CD (1:1) are demonstrated in Fig. 9b.

There was no difference in the morphological structures of the cells. Similarly, as demonstrated in Fig. 9a by MTT assay, the application of 5FU significantly increased the formazan production at both $\mathrm{pHs}$ : the administration of SBA-15_N-ANI_5-FUN_B-CD $(1: 1)$ at $\mathrm{pH}=7.3$ resulted in the same viability as the control U87 MG cells, whereas the viability of $\mathrm{U} 87 \mathrm{MG}$ cells at $\mathrm{pH}=6.3$ was significantly reduced at $24 \mathrm{~h}$ and $48 \mathrm{~h}$ after the administration of SBA-15_N-ANI_5-FUN_ $\beta$-CD (1:1) (Fig. 9b). We assume that at the longer ( $48 \mathrm{~h}$ ) incubation time cells consumed nutrition and partially decreases $\mathrm{pH}$ that enabled the release of 5-FU and NAP from SBA-15_N-ANI_5-FUN_ $\beta$-CD (Fig. 9a). The released 5-FU and NAP increased cytotoxicity of the system in U87 GM cells. This effect was confirmed when the cells were incubated at lower pH (Fig. 9b).
The apoptosis induced in SKBR3 cells by SBA-15_N-ANI_5-FUN_ $\beta$-CD (1:1 and 1:2) was studied with flow-cytometry, $48 \mathrm{~h}$ after the administration. The representative bright-field images of SKBR3 cells in the absence and presence of 5-FU, NAP, and SBA-15_N-ANI_5-FUN_ $\beta$-CD (1:1 and 1:2) are displayed in Fig. 10a. In these images, the presence of SBA-15_N-ANI_5-FUN_B-CD particles are clearly evidenced (black arrows in the zoomed images). These particles were localized in the extracellular space, close to the plasma membrane of the cells. We assume that the adsorption of SBA-15_N-ANI_5-FUN_ $\beta$-CD (1:1 and 1:2) into the plasma membrane occurred.

The particles adsorbed on the cell surface (plasma membrane) may change the optical parameters of detected system. The scattered light was measured with flow cytometry. The FSC and SSC parameters characterize the size and the density of cells. From Fig. 10b, it can be seen that the size of the cells (FSC value) is similar in all studied conditions. The granularity and the cell density increased after the administration of SBA-15_N-ANI_5-FUN_B-CD (1:1 and 1:2). The shift in the cell density was demonstrated with the black arrow in Fig. 10b. In the next step, we have studied if the SBA-15_N-ANI_5-FUN_B-CD (1:1 and 1:2) can trigger the apoptosis, and elevate oxidative stress level in the mitochondria. The AnnexinV/FITC labelled phosphatidylserine expressed in SKBR3 cells was detected and cross-correlated with MTO, a sensor of reactive oxygen species (Fig. 10c). The percentage of cells related to living cells (* in the image), apoptosis and cells with the dissipated mitochondrial membrane potential $\left(\Delta \Psi_{\mathrm{m}}\right)$ were denoted in histograms.

We can recognize the reduction of living cells, the increase of apoptotic populations and the decrease of MTO fluorescence in cells subjected to SBA-15_N-ANI_5-FUN_ $\beta$-CD (1:1 and 1:2). The decrease of MTO fluorescence suggests the generation of oxidative stress in cells. This oxidative stress could be the source that triggered the apoptosis observed. The same level of apoptotic cells was observed at both molar ratios of SBA-15_N-ANI_5-FUN_ $\beta$-CD (1:1 and 1:2). From these results, we can assume that the SBA-15_N-ANI_5-FUN_ $\beta$-CD is more effective than free 5-FU and NAP. 
a)
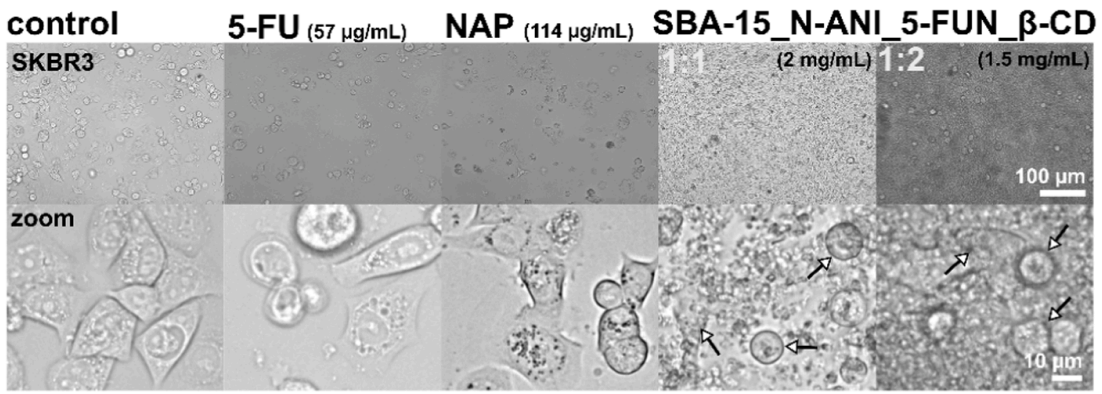

b)
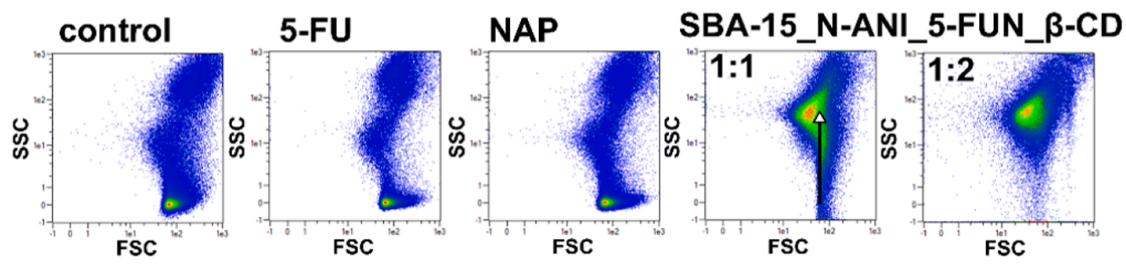

c)
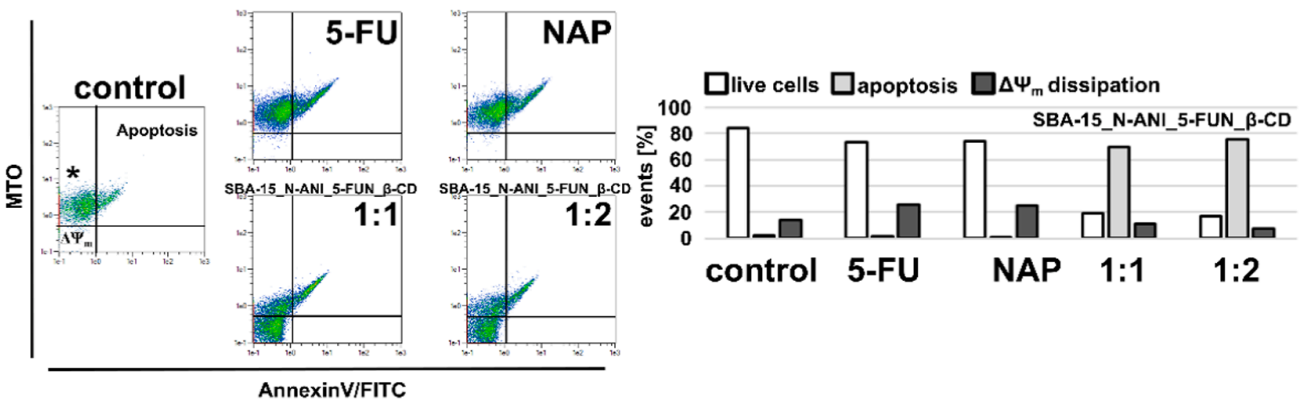

Fig. 10. Representative bright-field microscopic images a) of SKBR3 cells detected ( $48 \mathrm{~h}$ ) in the presence and absence of 5-FU, NAP, and SBA-15_N-ANI_5-FUN_ $\beta$-CD (1:1 and 1:2). b) Representative FSC vs. SSC correlation plots of the same samples detected by flow cytometry. c) Apoptosis (AnnexinV/FITC) and mitochondrial membrane potential (MTO) detected in SKBR3 cells at the same condition as in a) and b) by flow-cytometry. The number of events detected per population was plotted in a histogram. The number of events/cells in the plots were colour-coded (blue-minimum, red-maximum). The black arrows point to SBA-15_N-ANI_5-FUN_ $\beta$ CD particles.

\subsection{In vivo biocompatibility - CAM assay}

The CAM assay, in this study, was used to evaluate the biocompatibility of SBA-15_N-ANI_5-FUN_ $\beta$-CD with the live system, the quail CAM model of the microcirculatory system. This model is well established, cost-less, reproducible, and represents a simple model of a living cell membrane system with blood vasculature suitable for drug and delivery system studies. It is widely used as a preclinical model of biocompatibility and toxicity studies of drug/molecule/transport systems [58-60]. The importance of drug release in this study is in the release of drug from the transport system toward the CAM surface cells. The ectoderm (Ec) of CAM represents the first barrier for drug penetration into the embryo. In case of high toxicity, the membrane would be damaged, and embryo would not survive. Therefore, the main objective of this study was to test the biocompatibility of the prepared system with health - non-cancerous tissue.

The representative photographic images of CAM treated with 5-FU, NAP and SBA-15_N-ANI_5-FUN_ $\beta$-CD at different concentrations are demonstrated in Fig. 11. The solutions were topically applied to the area of silicone ring at $30 \mu \mathrm{L}$ of the volumes. It can be recognized that the application of 5-FU and NAP did not induce significant damage. A similar effect was observed at low concentrations $(0.3$ and $0.4 \mathrm{mg} / \mathrm{mL})$ of SBA-15_N-ANI_5-FUN_ $\beta$-CD applied on the CAM. However, the high concentrations (3 and $4 \mathrm{mg} / \mathrm{mL}$ ) of SBA-15_N-ANI_5-FUN_ $\beta$-CD created homogenous filter-like liquid surface (white colour), detected at $1 \mathrm{~min}$ after the administration (Fig. 11). Later, at $24 \mathrm{~h}$ after the administration, the applied SBA-15_N-ANI_5-FUN_ $\beta$-CD created bulky whitish clusters that did not penetrate through the ectoderm. The histological sections were taken at the end of the observation ( $24 \mathrm{~h}$ after the administration of the solutions).

The H\&E staining of histological sections of CAM treated with 5-FU and low concentration of SBA-15_N-ANI_5-FUN_B-CD displays similar patterns as the control (last row in Fig. 11). The histological section of the highest applied concentration of SBA-15_N-ANI_5-FUN_ $\beta$-CD showed that it induced damage to the CAM ectoderm.

The massive haemorrhages were observed in this sample and were denoted by the black arrow in the image. At our studied conditions, the release of the drugs (5-FU and NAP) from the nanoparticles towards CAM is very probable. However, the applied concentrations of drugs were below therapeutically applied doses related to CAM embryo.

In our study, the viability of the treated CAM on the second day was $100 \%$. This suggests that the SBA-15_N-ANI_5-FUN_B-CD are biocompatible with CAMs. The local damage of the CAM at the high applied concentrations could be explained as the result of the drug cytotoxicity in the area related to the whitish SBA-15_N-ANI_5-FUN_ $\beta$-CD aggregates. Similarly, but elsewhere, the rotigotine release from the polymeric nanoparticles induced the edema in the injection site [61]. To prevent the Ec damage, the SBA-15_N-ANI_5-FUN_ $\beta$-CD could be attached to some biocompatible scaffold to enable homogeneous distribution. Another explanation of the CAM damage could be that the created filter- 

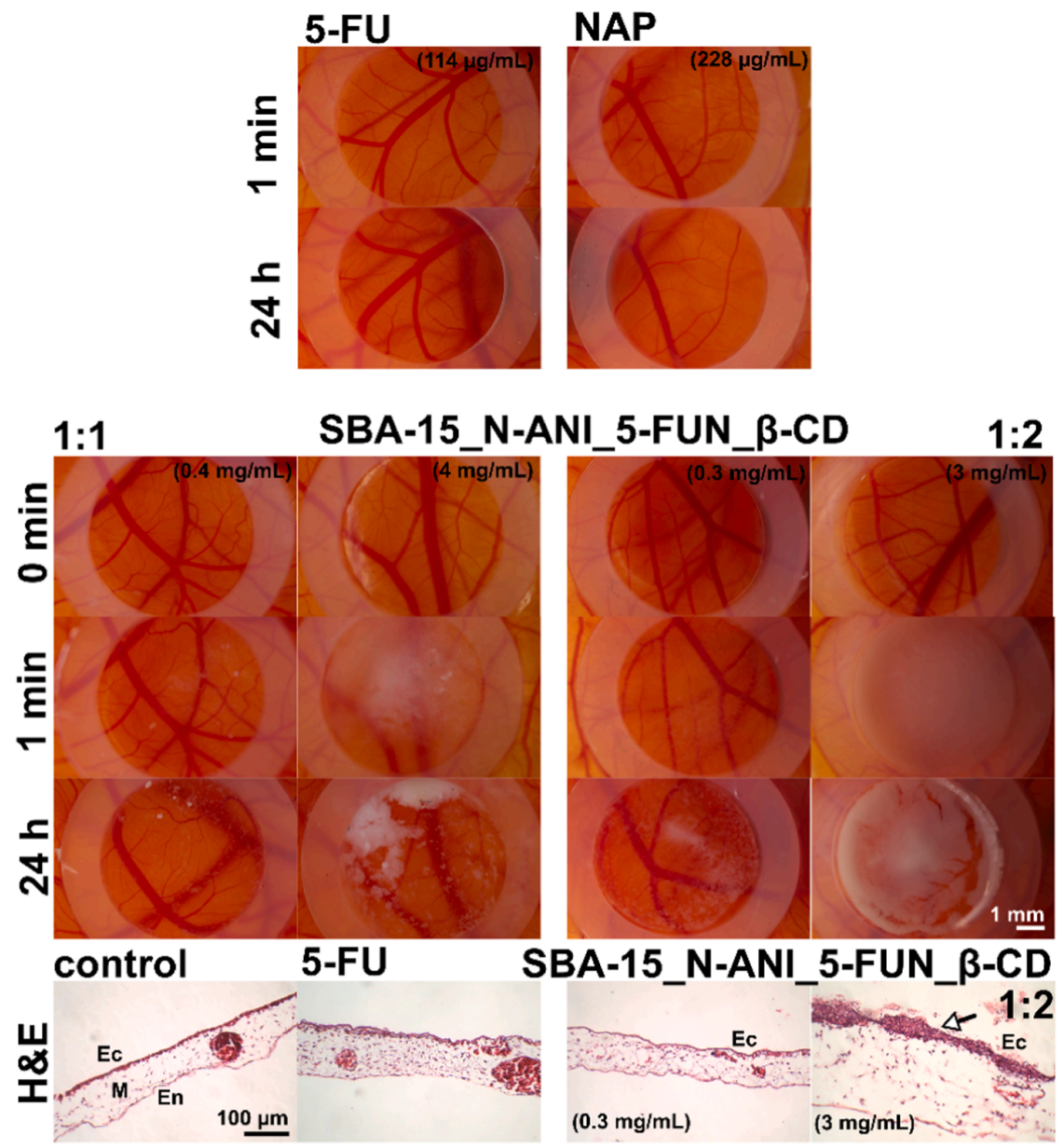

Fig. 11. Representative photographic images of quail CAM detected before and after administration of 5-FU, NAP and SBA-15_N-ANI_5FUN_ $\beta$-CD at the concentration ratio $1: 1$ and 1:2. The $30 \mu \mathrm{L}$ of the solutions were applied to the silicone ring to homogeneously cover the CAM surface. The H\&E staining was performed $24 \mathrm{~h}$ after the administration (Ec - ectoderm, M - mesoderm, En - endoderm). The black arrow points to Ec damage at higher concentration of SBA-15_N-ANI_5FUN_ $\beta$-CD.

like surface prevented the oxygenation of the tissue, resulting in hypoxia, and massive damage. A very similar effect was observed in the study of nanoceria with CAM-assay [60].

\section{Conclusions}

An advanced nanoporous system for $\mathrm{pH}$ driven drug delivery, based on $\mathrm{N}$-(propyl)aniline modified mesoporous silica and $\beta$-cyclodextrin $(\beta-C D)$ was prepared. The idea of the work was driven by the fact, that in the tumor tissues, the $\mathrm{pH}$ is slightly lower compared to the healthy cells represent by the standard physiological environment. For this reason, the system was designed to have pores closed at physiological $\mathrm{pH}=7.4$ and opened at a lower one, $\mathrm{pH}=5$. The system was tested for the codelivery of two different drugs: an anticancer agent (5-fluorouracil, 5FU) and anti-inflammatory drug (naproxen, NAP).

Before release experiments, a detailed study of drugs adsorption (adsorption of 5-FU and NAP each alone), and the co-adsorption of both drugs from mutual mixture was performed. It was evidenced that adsorbed amounts of NAP in the mixture were almost three times larger compared to the adsorption of a single NAP. In the case of 5-FU, no significant changes were observed.

It was shown that, at physiological $\mathrm{pH}=7.4$, the prepared drug delivery system was tight and only $16 \%$ of 5 -FU and $20 \%$ of NAP were released in first $3 \mathrm{~h}$. This release could be explained by the fact that not all pores were capped properly by $\beta$-CD molecules, which agrees with $\mathrm{N}_{2}$ adsorption/desorption measurements, where some mesoporosity was still observed after $\beta$-CD capping. However, no release of drugs was observed after these $3 \mathrm{~h}$. At $\mathrm{pH}=5$, the $\beta$-CD molecules were loosened, pores were opened and $89 \%$ of 5 -FU and $99 \%$ of NAP drug amounts released.

Biocompatibility and cytotoxicity studies were performed using U87 MG and SKBR3 cells. The MTT assay showed that, at physiological pH (7.4), SBA-15_N-ANI_5-FUN_ $\beta$-CD formulation protects the release of 5FU and NAP from the SBA-15_N-ANI_ $\beta$-CD towards the cells. A synergic effect induced by NAP was observed, and it was shown that 5 -FU can be delivered using SBA-15_N-ANI_5-FUN_ $\beta$-CD more effectively than 5-FU itself. The effect of $\mathrm{pH}$ on the cytotoxicity of SBA-15_N-ANI_5-FUN_ $\beta$ $\mathrm{CD}$ was tested in $\mathrm{U} 87 \mathrm{MG}$ cells at $\mathrm{pH}=7.3$ and 6.3. The administration of SBA-15_N-ANI_5-FUN_ $\beta$-CD at $\mathrm{pH}=7.3$ resulted in the same viability as the control U87 MG cells. The viability of U87 MG cells at $\mathrm{pH}=6.3$ was significantly reduced at the 24 and $48 \mathrm{~h}$ after the administration of SBA-15_N-ANI_5-FUN_ $\beta$-CD. Tests of in vivo biocompatibility in CAM assay showed the CAM ectoderm damage only at the highest applied concentration of SBA-15_N-ANI_5-FUN_B-CD.

\section{CRediT authorship contribution statement}

Eva Benova: Investigation, Data curation, Formal analysis, Visualization, Writing - original draft. Virginie Hornebecq: Conceptualization, Methodology, Formal analysis, Writing - original draft, Writing - 
review \& editing, Supervision, Project administration. Vladimír Zelenak: Conceptualization, Methodology, Formal analysis, Visualization, Writing - original draft, Writing - review \& editing, Supervision, Project administration, Funding acquisition. Veronika Huntosova: Investigation, Data curation, Formal analysis, Visualization, Writing - original draft. Miroslav Almasi: Formal analysis, Visualization, Writing - original draft. Mariana Macajova: Investigation, Data curation. David Berge-Lefranc: Investigation, Data curation.

\section{Declaration of Competing Interest}

The authors declare that they have no known competing financial interests or personal relationships that could have appeared to influence the work reported in this paper.

\section{Acknowledgements}

This work was supported by the Slovak Research and Development Agency under the contract APVV-15-0520. E.B thanks French Government for the financial support linked to the implementation of FrenchSlovak doctorate. V.Z. thanks the Ministry of Education, Science, Research and Sport of the Slovak Republic and the Accreditation Commission for the financial support of the TRIANGEL team in the frame of the scheme "Top Research Teams in Slovakia". This publication is also the result of the project implementation: "Open scientific community for modern interdisciplinary research in medicine (OPENMED)", ITMS2014+: 313011V455 supported by the Operational Programme Integrated Infrastructure, funded by the ERDF.

\section{Appendix A. Supplementary data}

Supplementary data to this article can be found online at https://doi. org/10.1016/j.apsusc.2021.150011.

\section{References}

[1] P. Borst, Looking back at multidrug resistance (MDR) research and ten mistakes to be avoided when writing about ABC transporters in MDR, FEBS Lett. 594 (2020) 4001-40011, https://doi.org/10.1002/1873-3468.13972.

[2] A. Wolfensberger, S.P. Kuster, M. Marchesi, R. Zbinden, M. Hombach, The effect of varying multidrug-resistence (MDR) definitions on rates of MDR gram-negative rods, Antimicrobial Resistance \& Infection Control 8 (2019) 193. https://doi. org/10.1186/s13756-019-0614-3.

[3] R.R. Castillo, M. Colilla, M. Vallet-Regí, Advances in mesoporous silica-based nanocarriers for co-delivery and combination therapy against cancer, Expert Opin. Drug Deliv. 14 (2017) 229-243, https://doi.org/10.1080/ 17425247.2016.1211637.

[4] J.L. Paris, M. Vallet-Regí, Mesoporous silica nanoparticles for co-delivery of drugs and nucleic acids in oncology: a review, Pharmaceutics 12 (2020) 526, https://doi. org/10.3390/pharmaceutics12060526.

[5] Z.Y. Li, Y. Liu, X.Q. Wang, L.H. Liu, J.J. Hu, G.F. Luo, W.H. Chen, L. Rong, X. Z. Zhang, One-pot construction of functional mesoporous silica nanoparticles for the tumor-acidity-activated synergistic chemotherapy of glioblastoma, ACS Appl. Mater. Interfaces 5 (2013) 7995-8001, https://doi.org/10.1021/am402082d.

[6] Q. Liu, J. Zhang, W. Sun, Q. Reuben Xie, W. Xia, H. Gu, Delivering hydrophilic and hydrophobic chemotherapeutics simultaneously, Int. J. Nanomed. 7 (2012) 999-1013, https://doi.org/10.2147/IJN.S28088.

[7] X. Li, M. Wu, L. Pan, J. Shi, Tumor vascular-targeted co-delivery of antiangiogenesis and chemotherapeutic agents by mesoporous silica nanoparticlebased drug delivery system for synergetic therapy of tumor, Int. J. Nanomed. 11 (2015) 93-105, https://doi.org/10.2147/IJN.S81156.

[8] Z. Gounani, M.A. Asadollahi, J.N. Pedersen, J. Lyngs $\varnothing$, J. Skov Pedersen, A. Arpanaei, R.L. Meyer, Mesoporous silica nanoparticles carrying multiple antibiotics provide enhanced synergistic effect and improved biocompatibility, Colloids Surf. B Biointerfaces 175 (2019) 498-508, https://doi.org/10.1016/j. colsurfb.2018.12.035.

[9] L. Jia, Z. Li, J. Shen, D. Zheng, X. Tian, H. Guo, P. Chang, Multifunctional mesoporous silica nanoparticles mediated co-delivery of paclitaxel and tetrandrine for overcoming multidrug resistance. Int. J. Pharm. 489 (2015) 318-330. https:// doi.org/10.1016/j.ijpharm.2015.05.010.

[10] M. Vallet-Regí, M. Colilla, I. Izquierdo-Barba, M. Manzano, Mesoporous silica nanoparticles for drug delivery: current insights, Molecules 23 (2017) 47, https:// doi.org $/ 10.3390 /$ molecules23010047.

[11] M.M. Abeer, P. Rewatkar, Z. Qu, M. Talekar, F. Kleitz, R. Schmid, M. Lindén, T. Kumeria, A. Popat, Silica nanoparticles: a promising platform for enhanced oral delivery of macromolecules, J. Control. Release 326 (2020) 544-555, https://doi. org/10.1021/acs.bioconjchem.8b00416.

[12] R.M. Pallares, P. Agbo, X. Liu, D.D. An, S.S. Gauny, S.E. Zeltmann, A.M. Minor, R J. Abergel, Engineering mesoporous silica nanoparticles for targeted alpha therapy against breast cancer, ACS Appl. Mater. Interfaces 12 (2020) 40078-40084, https://doi.org/10.1021/acsami.0c11051.

[13] R.R. Castillo, D. Lozano, B. González, M. Manzano, I. Izquierdo-Barba, M. ValletRegí, Advances in mesoporous silica nanoparticles for targeted stimuli-responsive drug delivery: an update, Expert Opinion on Drug Delivery, Expert Opinion on Drug Deliv. 16 (2019) 415-439, https://doi.org/10.1080/ 17425247.2019.1598375

[14] L. Huang, M. Liu, L. Mao, D. Xu, Q. Wan, G. Zeng, Y. Shi, Y. Wen, X. Zhang, Y. Wei, Preparation and controlled drug delivery applications of mesoporous silica polymer nanocomposites through the visible light induced surface-initiated ATRP, Appl. Surf. Sci. 412 (2017) 571-577, https://doi.org/10.1016/j. apsusc.2017.04.026.

[15] Y. Wang, Y. Cui, J. Huang, D. Di, Y. Dong, X. Zhang, Q. Zhao, N. Han, Y. Gao, T. Jiang, S. Wang, Redox and pH dual-responsive mesoporous silica nanoparticles for site-specific drug delivery, Appl. Surf. Sci. 356 (2015) 1282-1288, https://doi. org/10.1016/j.apsusc.2015.07.151.

[16] T. Zhao, L. Chen, Q. Li, X. Li, Near-infrared light triggered drug release from mesoporous silica nanoparticles, J. Mater. Chem. B 6 (2018) 7112-7121. https:// doi.org/10.1016/j.jconrel.2020.07.021.

[17] F. Liu, P. Huang, D. Huang, S. Liu, Q. Cao, X. Dong, H. Zhang, F. Ko, W. Zhou, Smart "on-off" responsive drug delivery nanosystems for potential imaging diagnosis and targeted tumor therapy, Chem. Eng. Journal 365 (2019) 358-368, https://doi.org/10.1016/j.cej.2019.02.037.

[18] T. Numpilai, T. Witoon, M. Chareonpanich, J. Limtrakul, Impact of physicochemical properties of porous silica materials conjugated with dexamethasone via $\mathrm{pH}$-responsive hydrazone bond on drug loading and release behavior, Appl. Surf. Sci. 396 (2017) 504-514, https://doi.org/10.1016/j. apsusc.2016.10.183.

[19] Y. Gao, Y. Xiao, K. Mao, X. Qin, Y. Zhang, D. Li, Y. Zhang, J. Li, H. Wan, S. He, Thermoresponsive polymer-encapsulated hollow mesoporous silica nanoparticles and their application in insecticide delivery, Chem. Eng. J. 383 (2020) 123169, https://doi.org/10.1016/j.cej.2019.123169.

[20] P. Joyce, H. Ulmefors, S. Maghrebi, S. Subramaniam, A. Wignall, S. Jõemetsa, F. Höok, C.A. Prestidge, Enhancing the cellular uptake and antibacterial activity of rifampicin through encapsulation in mesoporous silica nanoparticles, Nanomaterials 10 (2020) 815, https://doi.org/10.3390/nano10040815.

[21] M. Vallet-Regi, A. Rámila, R.P. del Real, J. Pérez-Pariente, A new property of MCM 41: drug delivery system, Chem. Mater. 13 (2001) 308-311, https://doi.org/ $10.1021 / \mathrm{cm} 0011559$.

[22] G. Marinescu, D.C. Culita, C. Romanitan, S. Somacescu, C.D. Ene, V. Marinescu, D. G. Negreanu, C. Maxim, M. Popa, L. Marutescu, M. Stan, C. Chifiriuc, Novel hybrid materials based on heteroleptic Ru(III) complexes immobilized on SBA-15 mesoporous silica as highly potent antimicrobial and cytotoxic agents, Appl. Surf. Sci. 520 (2020) 146379, https://doi.org/10.1016/j.apsusc.2020.146379.

[23] L. Hajiaghababaei, M. Eslambolipour, A. Badiei, M.R. Ganjali, G.M. Ziarani, Controlled release of anticancer drug using o-phenylenediamine functionalized SBA-15 as a novel nanocarrier, Chem. Papers 75 (2021) 1841-1850, https://doi. org/10.1007/s11696-020-01422-9.

[24] B. Malfait, N.T. Correia, C. Ciotonea, J. Dhainaut, J.P. Dacquin, S. Royer, N. Tabary, Y. Guinet, A. Hédoux, Manipulating the physical states of confined ibuprofen in SBA-15 based drug delivery systems obtained by solid-state loading: Impact of the loading degree, J. Chem. Phys. 153 (2020) 154506, https://doi.org/ 10.1063/5.0020992.

[25] S. Kingchok, S. Pornsuwan, Comparison of spherical and rod-like morphologies of SBA-15 for enzyme immobilization, J. Porous Mater. 27 (2020) 1547-1557, https://doi.org/10.1007/s10934-020-00932-x.

[26] F. Khanmohammadi, M.A. Molina, R.M. Blanco, S.N. Azizi, C. Marquez-Alvarez, I. Diaz, Microp. Mesop. Mater. 309 (2020) 1387-1811, https://doi.org/10.1016/j. micromeso.2020.110527.

[27] V. Zeleňák, D. Halamová, M. Almáśi, L. Žid, A. Zeleňáková, O. Kapusta, Ordered cubic nanoporous silica support MCM-48 for delivery of poorly soluble drug indomethacin, Appl. Surf. Sci. 443 (2018) 525-534, https://doi.org/10.1016/j. apsusc. 2018.02.260.

[28] M. Almáši, E. Beňová, V. Zeleňák, B. Madaj, V. Huntošová, J. Brus, M. Urbanová, J. Bednarčík, V. Hornebecq, Cytotoxicity study and influence of SBA-15 surface polarity and $\mathrm{pH}$ on adsorption and release properties of anticancer agent pemetrexed, Mater. Sci. Eng. C 109 (2020) 110552, https://doi.org/10.1016/j. msec.2019.110552.

[29] V. Zeleňák, E. Beňová, M. Almáši, D. Halamová, V. Hornebecq, V. Hronský, Photoswitchable nanoporous silica supports for controlled drug delivery, New J. Chem. 42 (2018) 13263-13271, https://doi.org/10.1039/C8NJ00267C.

[30] E. Beňová, V. Zeleňák, D. Halamová, M. Almáši, V. Petrul'ová, M. Psotka, A. Zeleñáková, M. Bačkor, V. Hornebecq, A drug delivery system based on switchable photo-controlled p-coumaric acid derivatives anchored on mesoporous silica, J. Mater. Chem. B 5 (2017) 817-825. https://doi.org/10.1039/C6TB02040B.

[31] E. Beňová, D. Bergé-Lefranc, V. Zeleňák, M. Almáši, V. Huntošová, V. Hornebecq, Adsorption properties, the $\mathrm{pH}$-sensitive release of 5-fluorouracil and cytotoxicity studies of mesoporous silica drug delivery matrix, Appl. Surf. Sci. 504 (2020) 144028, https://doi.org/10.1016/j.apsusc.2019.144028.

[32] D.B.G. Williams, M. Lawton, Drying of organic solvents: quantitative evaluation of the efficiency of several desiccants, J. Org. Chem. 75 (2010) 8351-8354, https:// doi.org/10.1021/jo101589h. 
[33] D. Zhao, J. Feng, Q. Huo, N. Melosh, G.H. Fredrickson, B.F. Chmelka, G.D. Stucky, Triblock Copolymer Syntheses of Mesoporous Silica with Periodic 50 to 300 Angstrom Pores, Science 279 (1998) 548-552, https://doi.org/10.1126/ science.279.5350.548.

[34] https://www.vanderbilt.edu/viibre/CellCultureBasicsEU.pdf, last accessed 7.1. 2021.

[35] J. Rouquerol, F. Rouquerol, P. Llewellyn, G. Maurin, K. Sing, Adsorption by powders and porous solids, first ed., Academic Press, Cambridge, Massachusetts, 2012.

[36] C.A. Cheng, T. Deng, F.C. Lin, Y. Cai, J.I, Zink, Supramolecular nanomachines as stimuli-responsive gatekeepers on mesoporous silica nanoparticles for antibiotic and cancer drug delivery, Theranostics, 9 (2019), 3341-3364. https://doi.org /10.7150/thno.34576.

[37] Z. Li, D.L. Clemens, B.Y. Lee, B.J. Dillon, M.A. Horwitz, J.I. Zink, Mesoporous silica nanoparticles with $\mathrm{pH}$-sensitive nanovalves for delivery of moxifloxacin provide improved treatment of lethal pneumonic tularemia, ACS Nano 24 (2015) improved treatment of lethal pneumonic tularemia, ACS Nand

[38] H. Meng, M. Xue, T. Xia, Y.-L. Zhao, F. Tamanoi, J.F. Stoddart, J.I. Zink, A.E. Nel, Autonomous in vitro anticancer drug release from mesoporous silica nanoparticles by pH-sensitive nanovalves, J. Am. Chem. Soc. 132 (2010) 12690-12697, https:// doi.org/10.1021/ja104501a.

[39] L. Bai, Q. Zhao, J. Wang, Y. Gao, Z. Sha, D. Di, N. Han, Y. Wang, J. Zhang, S. Wang, Mechanism study on pH-responsive cyclodextrin capped mesoporous silica: effect of different stalk densities and the type of cyclodextrin, Nanotechnology 26 (2015) 165704, https://doi.org/10.1088/0957-4484/26/16/165704.

[40] Z. Luan, J.A. Fournier, J.B. Wooten, D. Miser, Preparation and characterization of (3-aminopropyl)triethoxysilane-modified mesoporous SBA-15 silica molecular sieves, Microporous Mesoporous Mater. 83 (2005) 150-158, https://doi.org/ 10.1016/j.micromeso.2005.04.006.

[41] M. Thommes, K. Kaneko, A.V. Neimark, J.P. Olivier, F. Rodriguez-Reinoso, J. Rouquerol, K.S.W. Sing, Physisorption of gases, with special reference to the evaluation of surface area and pore size distribution (IUPAC technical report), Pure Appl. Chem. 87 (2015) 1051-1069, https://doi.org/10.1515/pac-2014-1117.

[42] J.C. Doadrio, E.M.B. Sousa, I. Izquierdo-Barba, A.L. Doadrio, J. Perez-Pariente, M. Vallet-Regí, Functionalization of mesoporous materials with long alkyl chains as a strategy for controlling drug delivery pattern, J. Mater. Chem. 16 (2006) 462-466, https://doi.org/10.1039/B510101H.

[43] L. Polo, N. Gómez-Cerezo, A. García-Fernández, E. Aznar, J.L. Vivancos, D. Arcos, M. Vallet-Regí, R. Martínez-Máñez, Mesoporous bioactive glasses equipped with stimuli-responsive molecular gates for controlled delivery of levofloxacin against bacteria, Chem. Eur. J. 24 (2018) 18944-18951, https://doi.org/10.1002/ chem. 201803301.

[44] S. Pathan, P. Solanki, A. Patel, Functionalized SBA-15 for controlled release of poorly soluble drug erythromycin, Microporous Mesoporous Mater. 258 (2018) 114-121, https://doi.org/10.1016/j.micromeso.2017.09.012.

[45] M. Hamzehloo, J. Karimi, K. Aghapoor, H. Sayahi, H.R. Darabi, The synergistic cooperation between MCM-41 and azithromycin: a pH responsive system for drug adsorption and release, J. Porous Mater. 25 (2018) 1275-1285, https://doi.org/ 10.1007/s10934-017-0538-3.

[46] A.M. El-Kady, M.M. Farag, A.M.I. El-Rashedi, Bioactive glass nanoparticles designed for multiple deliveries of lithium ions and drugs: curative and restorative bone treatment, Eur. J. Pharm. Sci. 91 (2016) 243-250, https://doi.org/10.1016/j. bone treatment, Eur.

[47] N. Zirak, A. Bolandparvaz Jahromi, E. Salahinejad, Vancomycin release kinetics from $\mathrm{Mg}-\mathrm{Ca}$ silicate porous microspheres developed for controlled drug delivery, Ceram. Int. 46 (2020) 508-512, https://doi.org/10.1016/j.ceramint.2019.08.290.

[48] S. Radin, T. Chen, P. Ducheyne, The controlled release of drugs from emulsified solgel processed silica microspheres, Biomaterials 30 (2009) 850-858, https://doi. org/10.1016/j.biomaterials.2008.09.066.
[49] T. Higuchi, Mechanism of sustained-action medication. Theoretical analysis of rate of release of solid drugs dispersed in solid matrices, J. Pharm. Sci. 52 (1963) 1145-1149, https://doi.org/10.1002/jps.2600521210.

[50] S. Kockisch, G.D. Rees, J. Tsibouklis, J.D. Smart, Mucoadhesive triclosan-loaded polymer microspheres for application to the oral cavity: preparation and controlled release characteristics, Eur. J. Pharm. Biopharm. 59 (2005) 207-216, https://doi. org/10.1016/j.ejpb.2004.07.007.

[51] J. Han, Y. Jun, S.H. Kim, H.H. Hoang, Y. Jung, S. Kim, J. Kim, R.H. Austin, S. Lee, S. Park, Rapid emergence and mechanisms of resistance by U87 glioblastoma cells to doxorubicin in an in-vitro tumor microfluidic ecology, Proc. Natl. Acad. Sci. 113 (2016) 14283-14288, https://doi.org/10.1073/pnas.1614898113.

[52] V. Němcová-Fürstová, D. Kopperová, K. Balušíková, M. Ehrlichová, V. Brynychová, D. Václavíková, P. Daniel, P. Souček, J. Kovár, Characterization of acquired paclitaxel resistance of breast cancer cells and involvement of ABC transporters, Toxicol. Appl. Pharmacol. 310 (2016) 215-228, https://doi.org/10.1016/j taap.2016.09.020.

[53] X.Y. Hu, J.Y. Liang, X.J. Guo, L. Liu, Y.B. Guo, 5-Fluorouracil combined with apigenin enhances anticancer activity through mitochondrial membrane potential $\left(\Delta \Psi_{\mathrm{m}}\right)$-mediated apoptosis in hepatocellular carcinoma, Clin. Exp. Pharmacol. Physiol. 42 (2015) 146-153, https://doi.org/10.1111/1440-1681.12333.

[54] H. Zhao, Q. Liu, S. Wang, F. Dai, X. Cheng, W. Chen, M. Zhang, D. Chen, In vitro additive antitumor effects of dimethoxycurcumin and 5-fluorouracil in colon cancer cells, Cancer Med. 6 (2017) 1698-1706, https://doi.org/10.1002 camcer cells,

[55] W. Liu, Y. Zhu, F. Wang, X. Li, X. Liu, J. Pang, W. Pan, Galactosylated chitosanfunctionalized mesoporous silica nanoparticles for efficient colon cancer celltargeted drug delivery, R. Soc. Open Sci. 5 (2018), https://doi.org/10.1098/ rsos. 181027.

[56] S. Zhou, C. Ding, C. Wang, J. Fu, UV-light cross-linked and pH de-cross-linked coumarin-decorated cationic copolymer grafted mesoporous silica nanoparticles for drug and gene co-delivery in vitro, Mater. Sci. Eng. C 108 (2020) 110469, https://doi.org/10.1016/j.msec.2019.110469.

[57] J. Fang, S. Zhang, X. Xue, X. Zhu, S. Song, B. Wang, L. Jiang, M. Qin, H. Liang, L. Gao, Quercetin and doxorubicin co-delivery using mesoporous silica nanoparticles enhance the efficacy of gastric carcinoma chemotherapy, Int. J. Nanomed. 13 (2018) 5113-5126, https://doi.org/10.2147/IJN.S170862.

[58] L. Blascakova, D. Horvath, D. Belej, G. Wagnieres, P. Miskovsky, D. Jancura, V. Huntosova, Hypericin can cross barriers in the chicken's chorioallantoic membrane model when delivered in low-density lipoproteins, Photodiagnosis Photodyn. Ther. 23 (2018) 306-313, https://doi.org/10.1016/j. pdpdt.2018.07.009.

[59] L. Lenkavska, L. Blascakova, Z. Jurasekova, M. Macajova, B. Bilcik, I. Cavarga, P. Miskovsky, V. Huntosova, Benefits of hypericin transport and delivery by lowand high-density lipoproteins to cancer cells: from in vitro to ex ovo, Photodiagnosis Photodyn. Ther. 25 (2019) 214-224, https://doi.org/10.1016/j pdpdt.2018.12.013.

[60] K. Siposova, V. Huntosova, Y. Shlapa, L. Lenkavska, M. Macajova, A. Belous, A. Musatov, Advances in the study of cerium oxide nanoparticles: new insights into antiamyloidogenic activity, ACS Appl. Bio Mater. 2 (2019) 1884-1896, https://doi org/10.1021/acsabm.8b00816.

[61] R.W. Moreadith, T.X. Viegas, M.D. Bentley, J.M. Harris, Z. Fang, K. Yoon, B. Dizman, R. Weimer, B.P. Rae, X. Li, C. Rader, D. Standaert, W. Olanow, Clinical development of a poly(2-oxazoline) (POZ) polymer therapeutic for the treatment of parkinson's disease - proof of concept of POZ as a versatile polymer platform for drug development in multiple therapeutic indications, Eur. Polym. J. 88 (2017) 524-552. https://doi.org/10.1016/j.eurpolymj.2016.09.052. 